\title{
Volatile organic compound fluxes over a winter wheat field by PTR-Qi-TOF-MS and eddy covariance
}

Benjamin Loubet ${ }^{1, *}$, Pauline Buysse ${ }^{1}$, Lais Gonzaga-Gomez ${ }^{1}$, Florence Lafouge ${ }^{1}$, Raluca Ciuraru $^{1}$, Céline Decuq ${ }^{1}$, Julien Kammer ${ }^{1, a}$, Sandy Bsaibes ${ }^{1,2}$, Christophe Boissard ${ }^{2,3}$, Brigitte

5 Durand $^{1}$, Jean-Christophe Gueudet ${ }^{1}$, Olivier Fanucci ${ }^{1}$, Olivier Zurfluh ${ }^{1}$, Letizia Abis ${ }^{1, b}$, Nora Zannoni $^{2, \mathrm{c}}$, François Truong ${ }^{2}$, Dominique Baisnée ${ }^{2}$, Roland-Sarda Esteve ${ }^{2}$, Michael Staudt $^{4}$ and Valérie Gros ${ }^{2}$.

1 Université Paris-Saclay, UMR ECOSYS, INRAE, AgroParisTech, 78850, Thiverval-Grignon, France.

2 Laboratoire des Sciences du Climat et de l'Environnement, LSCE, UMR CNRS-CEA-UVSQ, IPSL, 91191 Gif-

sur-Yvette, Île-de-France, France.

3 Université de Paris and UPEC, CNRS, LISA, F-94000 Créteil

4 Centre d'Ecologie Fonctionnelle et Evolutive UMR 5175, CNRS - Université de Montpellier - Université PaulValéry Montpellier - EPHE Campus CNRS, 1919 Route de Mende, F-34293 Montpellier cedex 5, France

15 a now at Department of Chemistry and Environmental Research Institute, University College Cork, T12 YN60 Cork, Ireland.

b now at Technische Universität Berlin, Umweltchemie und Luftrinhaltunz, Straße des 17. Juni 135, Berlin, 10623, Germany.

c now at Max-Planck Institute for Chemistry, Hahn-Meitner-Weg 1, 55128 Mainz, Germany

* Corresponding author: Benjamin.Loubet@inrae.fr

\begin{abstract}
Volatile organic compounds (VOC) contribute to air pollution through the formation of secondary aerosols and ozone and contribute to increasing the lifetime of methane in the atmosphere. Tropospheric VOC are $90 \%$ originating from biogenic sources at the global scale. Forests are the main contributors to these emissions with isoprene and monoterpenes being the most emitted compounds. Crops are also a potentially large, yet poorly characterised, source of VOC. In particular, measurements of VOC fluxes for wheat at the ecosystem scale are scarce, although this is the most cultivated crop in Europe. Available evidence indicates that crops may contribute to $30 \%$ of the VOC emissions in Europe, especially oxygenated, low-molecular-weight VOC such as methanol, acetone and acetaldehyde. In this study, we investigated VOC fluxes over a wheat field in-situ by eddy covariance using a PTR-Qi-TOF-MS with an outmost sensitivity and mass resolution. We found 264 compounds to have a flux three times above the flux detection limit. Methanol was the most emitted compound, with an averaged flux of $63 \mu \mathrm{g} \mathrm{m}^{-2} \mathrm{~h}^{-1}$, representing around $60 \%$ of summed VOC emissions on a molar basis (40\% on a mass basis). This finding is in line with previous measurements at canopy and plant scales. We also measured acetone, acetaldehyde and dimethyl sulphide among the five most emitted compounds. The second most emitted VOC corresponded to the ion $\mathrm{m} / \mathrm{z} 93.037$, tentatively identified as $\mathrm{C}_{6} \mathrm{H}_{4} \mathrm{O}$, a compound not reported previously as most emitted by crops. Summed VOC emissions amounted around $150 \mu \mathrm{g} \mathrm{m}^{-2} \mathrm{~h}^{-1}$, while summed VOC deposition amounted around $-125 \mu \mathrm{g} \mathrm{m}^{-2} \mathrm{~h}^{-1}$, which represented about $70 \%$ of the VOC emissions on a mass basis. The most depositing VOC were tentatively identified as hydroxyacetone and fragments of oxidised VOC with a flux of $16 \mu \mathrm{g} \mathrm{m}^{-2} \mathrm{~h}^{-1}$. Overall, our results reveal that wheat fields represent a non-negligible source and sink of VOC to be considered in regional VOC budgets, and underline the usefulness and limitations of eddy covariance measurements with a PTR-Qi-TOF-MS.
\end{abstract}

Keywords: VOC, crop, flux, Eddy covariance, methanol, DMS, deposition, emission 


\section{Introduction}

Volatile organic compounds (VOC) are key compounds for atmospheric chemistry that contribute to the production of harmful pollutants to human health, among which ozone $\left(\mathrm{O}_{3}\right)$ and secondary organic aerosols (SOA) (Lang-Yona et al., 2010; Monks et al., 2015). Ozone is also a powerful greenhouse gas (IPCC, 2018) that affects vegetation growth with an estimated annual cost of \$11-18 billion on agricultural production worldwide in the last decade (Ashmore, 2005; Avnery et al., 2011). Similarly, particulate matter (PM) affects directly and indirectly global warming by modifying radiation scattering and the cloud albedo (Makkonen et al., 2012). The official directives regarding VOC emissions are not very restrictive. The main regulations in Europe, resulting from the 1999 Gothenburg Protocol, concern the limitation of emissions from industrial plants and the limitation of concentrations in consumer products. Fine particles $\left(\mathrm{PM}_{2.5}\right)$ on the other hand are more regulated. European countries must meet air pollution targets set by the European Air Quality Directive (2008/50/EC). Thus, since VOC are precursors of harmful air pollutants, their sources must be better quantified to identify potential levers that could be used to mitigate the $\mathrm{PM}_{2.5}$ and ozone threats.

Of the $760 \mathrm{Tg}(\mathrm{C}) \mathrm{yr}^{-1}$ VOC emitted globally, it is estimated that around $90 \%$ are from the biogenic origin (BVOC) (Sindelarova et al., 2014). Forests are the main emitters and isoprene is the most emitted compound worldwide. In Europe, managed ecosystems (crops, managed grasslands and forests) representing about $50 \%$ of the land area, are the largest VOC source in the continent. According to Karl et al. (2009a), in Europe forests account for $55 \%$ of the total emission, agricultural lands for $27 \%$, and grasslands, wetlands and shrubs for $18 \%$. These values are however based on few datasets of BVOC fluxes (Keenan et al., 2009) and this is especially the case for crops. This leads to uncertainties in the estimates of VOC fluxes from this type of ecosystem. So far, few studies investigated VOC fluxes from crops on chambers (Copeland et al., 2012; Crespo et al., 2013; Das et al., 2003; Eller et al., 2011; Gonzaga Gomez et al., 2019; Graus et al., 2013; Konig et al., 1995; Wiss et al., 2017). Flux measurements at canopy level on crops are still rare, and rather focused on orchards and grasslands (Bachy et al., 2020; Bachy et al., 2018; Bachy et al., 2016; Berhongaray et al., 2017; Brilli et al., 2016; Copeland et al., 2012; Fares et al., 2012; Karl et al., 2001; Karl et al., 2005; Miresmailli et al., 2013; Misztal et al., 2014; Portillo-Estrada et al., 2018; Zenone et al., 2016). Gallagher et al. (2000) studied BVOC fluxes from above arable land by relaxed eddy accumulation. Bachy et al. (2016) reported fluxes of isoprene, monoterpenes, methanol, acetone, acetaldehyde and acetic acid from a maize field, which revealed lower emission than those parameterised in the MEGAN and ORHIDEE models (Messina et al., 2016). In a follow-up study, Bachy et al. (2020) reported the first measurements of VOC fluxes above a winter wheat field by eddy covariance with a quadrupole PTRMS. More measurements have been reported above grassland (Bamberger et al., 2010; Custer and Schade, 2007; Muller et al., 2010; Ruuskanen et al., 2011).

75 Reported VOC emission rates from crops are variable over a wide range of values as shown by Gonzaga et al. (2019) and Bachy et al. (2016). Thus, more data are required to consolidate emissions. Studies measuring ecosystem scale fluxes are particularly useful, since they integrate VOC sources and sinks throughout the canopy. For example, Bachy et al. (2018) showed that methanol may be emitted from bare agricultural soils in comparable quantities than from plants. The emergence of highly sensitive PTR-TOF-MS (Sulzer et al., 2014) enables the detection of a lot more VOC than with previous quadrupoles PTRMS, and allows ecosystem scale measurement of their fluxes by direct eddy covariance instead of virtual disjunct eddy covariance. This opens the possibility to get a much more complete spectrum of VOC emitted by crops than in previous studies. The objective of this study 
was therefore to quantify the fluxes of VOC exchanged between a winter wheat field and the atmosphere at the ecosystem scale using the eddy-covariance method, over periods of flowering, grain filling and senescence, using a highly sensitive PTR-Qi-TOF-MS. The methodology to compute the fluxes and their uncertainties is presented in detail, and the emission and deposition fluxes are discussed in terms of their magnitude and temporality.

\section{Methods}

\subsection{Experimental site and crop management}

Flux measurements took place at the Integrated Carbon Observation System (ICOS) FR-Gri site (Grignon, $48^{\circ} 51^{\prime} \mathrm{N}, 1^{\circ} 58^{\prime} \mathrm{E}$ ) located about $30 \mathrm{~km}$ west of Paris (France), between the $3^{\text {rd }}$ of June and the $19^{\text {th }}$ of July 2016. The site is a 19 ha field (Figure 1), with a crop rotation of wheat, maize, barley and occasionally rapeseed, and with a winter cover crop before maize. The soil is classified as Luvisol consisting of $25 \%$ clay, $70 \%$ silt, and $5 \%$ sand. More details about the site can be found in Loubet et al. (2011). The site that is part of a dairy farm receives a lot of nitrogen as mineral or organic matter, which leads to large ammonia emissions (Personne et al., 2015). The field was also shown to be a source of NO (Vuolo et al., 2017) and HONO (Laufs et al., 2016). The field is at around $450 \mathrm{~m}$ from the farm buildings, with about 250 dairy cows and 900 lambs. The farm has a storage tank for manure and storage areas. The farm buildings were shown to be a large source of ammonia that can be detected from the field site (Loubet et al., 2012). Similarly, Kammer et al. (2020) have shown that the animal farm is a consistent source of VOC and especially methanol, ethanol and acetaldehyde, but also a specific source of trimethylamine and dimethylsulfide (DMS) that might hence be detected at the field site.

Winter wheat was sown on 20/10/2015 at a density of 2500000 plant ha $^{-1}$, as a mixture of three varieties (Rubisco, Atlass and Premio). The crop was fertilised 4 times with nitrogen solution $\left(25 \% \mathrm{NO}_{3}, 25 \%, \mathrm{NH}_{4}, 50 \%\right.$ urea) at a rate of $84,39,39$ and $55 \mathrm{~kg} \mathrm{~N} \mathrm{ha}^{-1}$ on 01/03/2016, 09/04/2016, 29/04/2016 and 10/05/2016. Following the emergence of brown rust or septoria, the crop was sprayed with a fungicide the 13/04/2016 (Cherokee; cyproconazole $\mathrm{g} \mathrm{L}^{-1}$, propiconazole $62.5 \mathrm{~g} \mathrm{~L}^{-1}$, chlorothalonil $375 \mathrm{~g} \mathrm{~L}^{-1}$, at a rate of $\left.1.25 \mathrm{~L} \mathrm{ha}^{-1}\right), 16 / 05 / 2016$ (bixafen $75 \mathrm{~g} \mathrm{~L}^{-1}$ and prothioconazole $150 \mathrm{~g} \mathrm{~L}^{-1}$ at a rate of $\left.0.7 \mathrm{~L} \mathrm{ha}^{-1}\right)$, and 04/06/2016 (250 $\mathrm{g} \mathrm{L}^{-1}$ azoxystrobine at a rate of $\left.0.27 \mathrm{~L} \mathrm{ha}^{-1}\right)$. The crop was harvested on $28^{\text {th }}$ of July 2016 with a quite small yield of $4.310^{3} \mathrm{~kg} \mathrm{DW} \mathrm{ha}^{-}$ ${ }^{1}$. The crop started flowering on $20 / 05$ and was fully flowered on $01 / 06 / 2016$. The above ground biomass consisted of green leaves (13\% and $0 \%$ ), yellow leaves ( $4 \%$ and $14 \%$ ), stems (65\% and $45 \%)$, and grain ear (17\% and $41 \%)$ on 09/03/2016 and 28/07/2016 respectively. The maximum LAI of green leaves was $7.3 \mathrm{~m}^{2} \mathrm{~m}^{-2}$ on 25/05 and was down to $3.4 \mathrm{~m}^{2} \mathrm{~m}^{-2}$ on 09/06. Finally, the canopy height varied from 0.9 to $1.1 \mathrm{~m}$ during the experiment with quite large variability in the field $(0.15 \mathrm{~m}$ standard deviation) 


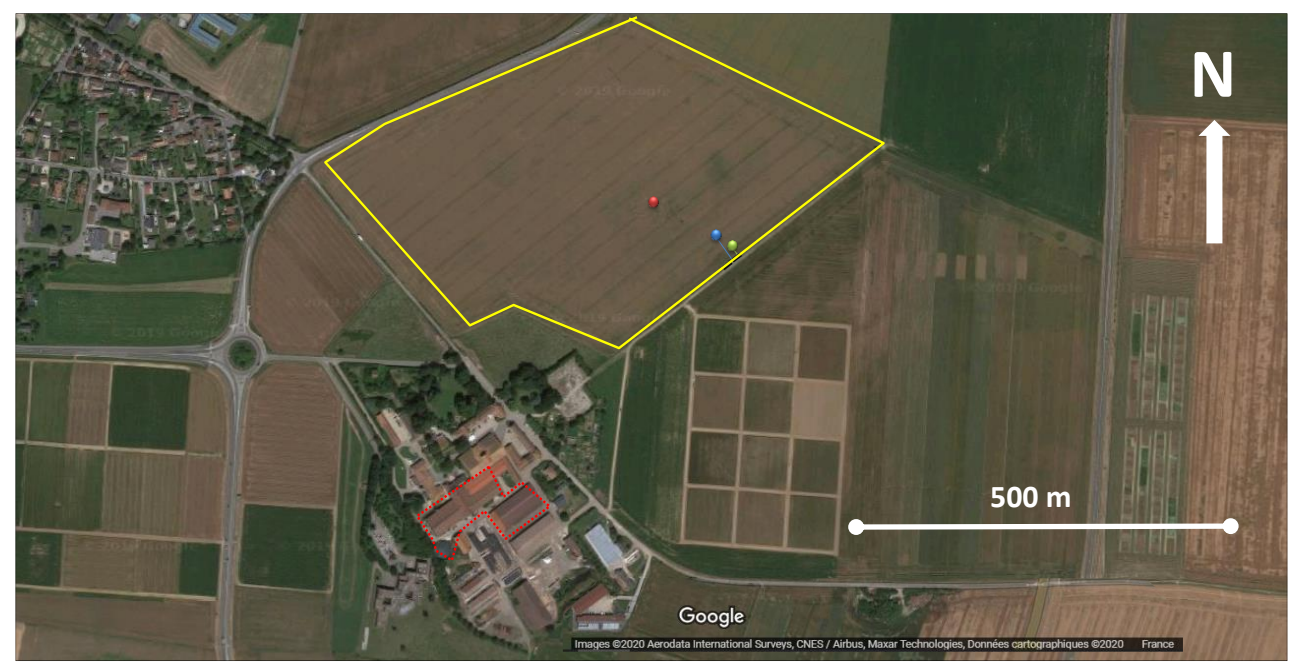

Figure 1. Satellite image of the site showing the ICOS FR-GRI field (yellow line), the ICOS flux station (red dot) the VOC Eddy Covariance sampling site (blue dot), and the VOC profile sampling site (green dot). The dotted red line shows the Farm buildings where animals are mainly stored, on the southeast of the field. () Google Earth.

\subsection{Volatile organic compounds measurements}

\subsubsection{VOC eddy covariance sampling system}

The VOC measurement strategy consisted of 30 minutes cycles. The eddy-covariance flux was measured over 20 min, while the last 10 minutes were devoted to vertical profiles $(5 \mathrm{~min})$ and chambers $(3 \mathrm{~min}) \mathrm{mixing}$ ratio measurements and zero checks ( $2 \mathrm{~min}$ ) by sampling through a hydrocarbon filter (Supelco ref 22445-12). In this study, the profiles and chamber measurements are not presented. A 16-way Sulfinert coated valve, located at $5 \mathrm{~cm}$ from the drift tube of the PTR-Qi-TOF-MS and heated to $80^{\circ} \mathrm{C}$ was used to switch between the Eddy-covariance and other channels. All sampling tubes were made of Teflon PFA (PerFluoroAlkoxy) surrounded by heating tape inserted in an insulator. Tubes were heated and regulated to $60^{\circ} \mathrm{C}$ using a homemade thermostated device and connected to the PTRMS inlets heated to $80^{\circ} \mathrm{C}$ to avoid any cold trap. A stainless steel manifold made of Swagelok T-fittings was used to sub-sample the air from the covariance line to the PTRMS and other instruments. The residence time in the tube was 2.15 seconds on average for the covariance line, which was made of a $1 / 2$ inch (external) tubing flushed with a $42 \mathrm{~L} \mathrm{~min}^{-1}$ air flow rate with a Busch SV-1010 pump (Busch, SW). This large flow rate was designed to minimize any chemical reaction and insure a turbulent flow to keep the high frequency structure of the concentrations fluctuations for the eddy covariance method. The end pressure in the line was 240 mbar below ambient pressure. Air from the covariance line was subsampled at $0.5 \mathrm{~L} \mathrm{~min}^{-1}$ with a $1 \mathrm{~m} \mathrm{long} 1 / 8$ inch external diameter PFA tubing heated at $80^{\circ} \mathrm{C}$ connected to the 16 -way valve.

The VOC Eddy-Covariance mast comprised: a sonic anemometer (R3-50, Gill, UK) put at the reference height of $2.7 \mathrm{~m}$ above ground, and an open path IRGA for $\mathrm{CO}_{2}$ and $\mathrm{H}_{2} \mathrm{O}$ (Li-7500, LICOR, USA) placed at $0.2 \mathrm{~m}$ apart on the east and $0.1 \mathrm{~m}$ below the anemometer centre (Figure 2). The covariance line head that sampled air to the PTRQi-TOF-MS was placed $0.1 \mathrm{~m}$ on the east and $0.2 \mathrm{~m}$ below the anemometer centre. The eddy covariance line head was made of a stainless steel cup $(\sim 2.5 \mathrm{~cm}$ diameter with a $1 \mathrm{~mm}$ mesh Teflon screen). The covariance line was 
used for VOC fluxes and mixing ratio measurements as well as for $\mathrm{CH}_{4}, \mathrm{~N}_{2} \mathrm{O}, \mathrm{H}_{2} \mathrm{O}, \mathrm{NO}_{\mathrm{x}}$ and $\mathrm{O}_{3}$ mixing ratios. Ozone and $\mathrm{NO}_{\mathrm{x}}$ analysers required a teflonised pump to increase pressure to ambient.

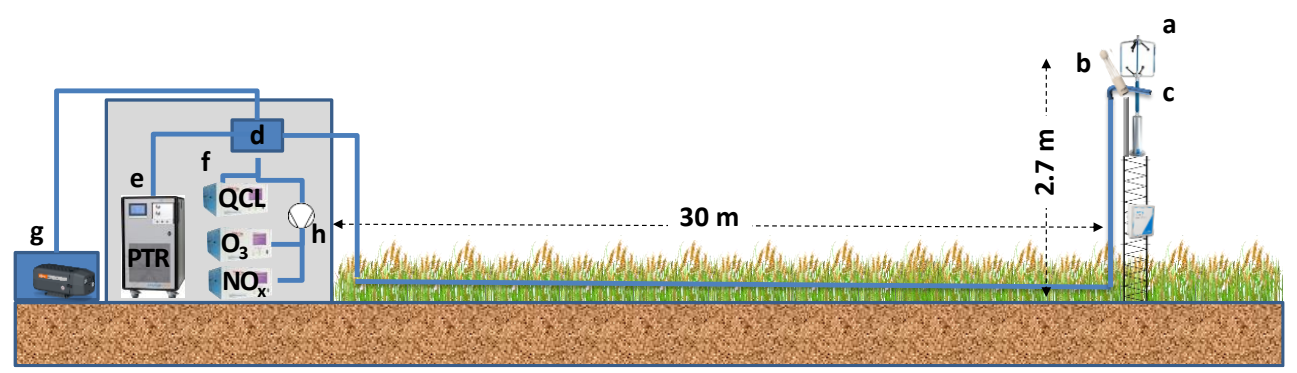

Figure 2. The eddy covariance VOC measurement setup, showing (a) the ultrasonic anemometer, $(\mathrm{b})$ the $\mathrm{CO}_{2}$ and $\mathrm{H}_{2} \mathrm{O}$ open path analyser, (c) the heated sampling line inlet, (d) the heated manifold, (e) the PTR-Qi-TOF-MS, (f) the gas analysers, (g) the high volume vacuum pump, and (h) the teflonised subsampling pump. Diagram not to scale.

\subsubsection{PTR-Qi-TOF-MS instrument setup}

A PTR-Qi-TOF-MS (Ionicon Analytik GmbH, Innsbruck, Austria) was used for continuous online measurements of VOC mixing ratios at $10 \mathrm{~Hz}$. The analyser was described in detail before (Abis et al., 2018; Sulzer et al., 2014). VOC are protonated inside a reaction tube, then are focused by a quadrupole ion guide and electromagnetic lenses before their separation into the time-of-flight mass spectrometer (ToF, TofWerk, Switzerland), which separates the ions by inertia prior to their detection on a multi-channel-plate (MCP) coupled to a time-to-digital converter (Burle Industries Inc., Lancaster, PA, USA). The drift tube was maintained at $3.5 \pm 0.001 \mathrm{mbar}$ and a temperature of $80 \pm 0.16^{\circ} \mathrm{C}$, while the drift voltage $\mathrm{E}$ was set to $995 \pm 0.8 \mathrm{~V}$ before the $29 / 06$ and to $848 \pm 0.3 \mathrm{~V}$ after. The corresponding $\mathrm{E} / \mathrm{N}$ ratios (where $\mathrm{E}$ is the electric field strength and $\mathrm{N}$ the gas density) were $150.66 \pm 0.15 \mathrm{Td}$ and $129.03 \pm 0.21 \mathrm{Td}\left(1\right.$ Townsend $\left.=10^{-17} \mathrm{~V} \mathrm{~cm}^{-2}\right)$. The E/N ratio at the start of the experiment was rather high and was hence lowered down to $129 \mathrm{Td}$ in the second half of the experiment to diminish cluster formation and fragmentation (Pang, 2015; Tani et al., 2003). The number of detection channels was set to 240000 and the mass spectrum spanned m/z 15 to $\mathrm{m} / \mathrm{z} 530$. The extraction rate of ions in the ToF was set to $40 \mu \mathrm{s}(25 \mathrm{kHz})$, meaning that 2500 extracted spectra were averaged before being recorded at $10 \mathrm{~Hz}$.

\subsubsection{Acquisition and pre-processing of PTR-Qi-TOF-MS data}

A data acquisition software was developed on Labview to synchronize the measurements of the PTR-Qi-TOF-MS with the sonic anemometer and the other fast-response instruments, and store the data. This software was based on the acquisition of a list of ion peaks integrated online by the TOFDaq software (TOFWERK, SW) using shared variables that are exchanged between the acquisition computer and the PTR-Qi-TOF-MS computer via a local Ethernet connexion. The desired ion peak list was set up at the start of the experiment based on a list of known compounds tuned to the site. The acquired ion peak integrals counts per seconds (cps) were synchronized at $20 \mathrm{~Hz}$ with the ultrasonic anemometer. Every 5 minutes, a mass calibration was performed by the TOFDaq software using masses $\mathrm{m} / \mathrm{z} 21.0221\left(\mathrm{H}_{3}{ }^{18} \mathrm{O}^{+}\right)$and $\mathrm{m} / \mathrm{z} 59.049$ (acetone $\mathrm{C}_{3} \mathrm{H}_{6} \mathrm{OH}^{+}$). When the calibration of these masses shifted from the real masses by more than $0.005 \mathrm{~m} / \mathrm{z}$ the 5 minutes record was discarded. Additionally, the quality of the peak integration was verified a posteriori by integrating several spectra with PTRMS Viewer (Ionicon, 
V3.3). We found errors lower than 5\% for most of the compounds in the most emitted ions as shown by Gonzaga et al., (2019). The synchronized data, stored every five minutes in binary files, were pre-processed with another Labview program to compute the mixing ratios and fluxes.

\subsubsection{VOC mixing ratio computation}

The pre-processing steps provided averages and standard deviations counts per seconds (cps) for the ion peaks selected $\mathrm{R}_{\mathrm{i}}$. The mixing ratio of the compound $\chi_{i, p t r}$ (in ppb) prior to any calibration, was calculated as:

$\chi_{i, p t r}=1.657 e^{-11} \times \frac{\mathrm{U}_{\text {drift }} \mathrm{T}_{\text {drift }}^{2}}{\mathrm{kp}_{\text {drift }}^{2}} \times\left(\frac{c p s s_{\mathrm{R}_{\mathrm{H}} \mathrm{H}^{+}}^{\text {trans }}}{c p \mathrm{H}_{\mathrm{H}_{3} \mathrm{O}^{+}}^{\text {trans }}+c p s_{\mathrm{H}_{2} \mathrm{O} \cdot \mathrm{H}_{3} \mathrm{O}^{+}}^{\text {trans }}}\right)$

$c p s_{\mathrm{R}_{\mathrm{i}} \mathrm{H}^{+}}^{\text {trans }}=\frac{\mathrm{TR}_{\mathrm{H}_{3} \mathrm{O}^{+}}}{\mathrm{TR}_{\mathrm{R}_{\mathrm{i}} \mathrm{H}^{+}}} \times c p s_{\mathrm{R}_{\mathrm{i}} \mathrm{H}^{+}}$

where $U_{\text {drift }}$ is the voltage of the drift tube $(V), T_{\text {drift }}$ is the drift tube temperature in Kelvin $(K), c p s_{\mathrm{R}_{\mathrm{i}} \mathrm{H}^{+}}$is the cps of the product ion $i, c p S_{\mathrm{H}_{3} \mathrm{O}^{+}}$and $c p s_{\mathrm{H}_{2} \mathrm{O} . \mathrm{H}_{3} \mathrm{O}^{+}}$are the cps of the ion source and the first water cluster, $\mathrm{k}$ is the proton transfer reaction rate assumed constant for all compounds $\left(2.510^{-9} \mathrm{~cm}^{3} \mathrm{~s}^{-1}\right)$, trans stands for normalised for transmission, $\mathrm{TR}_{\mathrm{H}_{3} \mathrm{O}^{+}}$is the transmission factor for $\mathrm{H}_{3} \mathrm{O}^{+}, \mathrm{TR}_{\mathrm{R}_{\mathrm{i}} \mathrm{H}^{+}}$is the transmission factor for the product ion $i$, $\mathrm{p}_{\text {drift }}$ is the pressure in the drift. The transmission curve from supplier was used to compute the transmission. $c p s_{\mathrm{H}_{3} \mathrm{O}^{+}}^{\text {trans }}$ was computed from ion $\mathrm{m} / \mathrm{z} 21.022\left(\mathrm{H}_{3}{ }^{18} \mathrm{O}^{+}\right)$by multiplying by the isotopic factor of $\mathrm{O}^{18} / \mathrm{O}^{16}$ in water 487.56, the first water cluster was taken as the ion peak $\mathrm{m} / \mathrm{z} 37.028$.

\subsubsection{Calibration procedures}

The PTR-Qi-ToF-MS calibration factor was measured several times during the experiment. To that purpose, we used a standard calibration mixture cylinder containing $102 \mathrm{ppb}$ of benzene, $104 \mathrm{ppb}$ of toluene, and $130 \mathrm{ppb}$ of ethylbenzene and $336 \mathrm{ppb}$ of xylene (122 ppb Ortho, $121 \mathrm{ppb}$ Meta, 123 ppb Para; BTEX, Messer). The gas mixture from this cylinder was diluted with synthetic air (Alphagaz 1, Air Liquide, FR), filtered with a hydrocarbons and humidity filter (Filter Super Clean, final purity=99.9999\%, Restek) and a Hydrocarbon Trap (Supelco, Supelpure HC). Two fluorinert coated mass flow controllers (Bronkhorst) were used for dilution to generate concentrations from zero to $50 \mathrm{ppb}$.

The background concentration was determined during each calibration using synthetic air passed through a hydrocarbon filter (Supelco ref 22445-12) for 2 minutes, and keeping the last 30 seconds of the record. The background was also determined every 30 minutes by passing ambient air through the same filter to account for the ambient humidity in the zero calibration. The background concentration was determined as the minimum between a 10-days moving minimum applied to the zero measured every 30 minutes and the zero measured during the calibrations. This procedure was used since the zero air calibration was sometimes much larger than the one measured with filtered ambient air. The zero was then withdrawn from the uncalibrated mixing ratio at hourly time steps, providing the zero corrected mixing ratio $\chi_{i, p t r}{ }^{*}$ :

$\chi_{i, p t r}{ }^{*}=\chi_{i, p t r}-\chi_{i, p t r}($ zero air $)$

205 The calibration factor $S_{i}$ was calculated as the slope of the regression between $\chi_{i, p t r}{ }^{*}$ and the prescribed mixing ratio during calibrations (forcing a zero intercept). We computed a single calibration factor for all VOC using toluene, to avoid issues of ethylbenzene fragmentation. The calibration factor was adjusted in time based on the 
five calibrations made during the course of the experiment as well as on E/N and MCP adjustment (see Table S1). For methanol, the calibration factor was 2.66 times the one for all other gases based on specific calibration performed in 2017 (See Gonzaga et al. 2019 for details). Finally, the calibrated mixing ratio was computed as:

$\chi_{i}=S_{i} \times \chi_{i, p t r}{ }^{*}=S_{i} \times\left(\chi_{i, p t r}-\chi_{i, p t r}(\right.$ zero air $\left.)\right)$

The calibration factor and zero for water vapour were computed hourly using a linear regression between

$\chi_{H 2 O . H 2 O . H+, p t r}$ and $\chi_{H 2 O, L i 7500}$.

\subsubsection{VOC eddy-covariance fluxes computation}

The fluxes were computed as the covariance between the vertical component of the wind velocity and the mixing ratio in dry air $\chi_{i, d}$, neglecting the Webb Penman Leuning density correction terms (Leuning, 2007). Indeed, we assumed that the drift temperature was not co-varying with wind velocity, which is a sensible assumption given that the PTR chamber is temperature controlled and given the high thermal mass of the PTR chamber compared to the air mass flowing into the instrument every minute. In these circumstances, the PTR chamber temperature was assumed independent of the air temperature, and the flux was computed as:

$F_{i}=\frac{\overline{p_{a} d}}{R \overline{T_{a}}} \overline{w^{\prime} \chi_{l, d}}$

where $F_{i}$ is the flux (nmol m $\left.\mathrm{m}^{-2} \mathrm{~s}^{-1}\right), \chi_{i, d}$ is the compound mixing ratio in dry air measured by the PTR (ppb), $w$ is the vertical wind component $\overline{T_{a}}$ is the air temperature $(\mathrm{K}), \overline{p_{a}{ }^{d}}$ the dry air pressure $(\mathrm{Pa})$ and $R$ is the perfect gas constant $\left(8.31 \mathrm{~J} \mathrm{~mol}^{-1} \mathrm{~K}^{-1}\right)$. Overbars $\left(^{-}\right)$denote averages and primes denote fluctuations following the Reynolds decomposition. Here $w^{\prime}$ was calculated by applying two rotations following Aubinet et al. (2000). The covariance between $\chi_{i, d}$ and $w^{\prime}$ was calculated after dephasing the two signals with a lag time $\tau$ computed as the time at which the correlation function $\overline{w^{\prime}(t) \chi_{l, d}{ }^{\prime}(t-\tau)}$ was the largest in absolute value (Figure S4). The lag time was set equal for all compounds as the average of the lag time computed for the water cluster, methanol and acetone, which showed very consistent correlation functions between 2.0 and $2.5 \mathrm{~s}$. To compute the covariance, the lag time was constrained between 2.0 and $2.3 \mathrm{~s}$ with a fixed value of $2.15 \mathrm{~s}$ if the lag exceeded this range. This was made in order not to bias the fluxes by letting the lag vary too much as explained in Langford et al. (2015).

Since the PTR measures a mixing ratio in wet air $\chi_{i}$, some corrections arise in eq. (5), to account for dilution by water vapour on $\chi_{i, d}$. Moreover, since the mixing ratio is computed by normalising with $c p s_{\mathrm{H}_{3} \mathrm{O}^{+}}^{\text {trans }}+c p s_{\mathrm{H}_{2} \mathrm{O} \mathrm{H}_{3} \mathrm{O}^{+}}^{\text {trans }}$ (Eqns. 1 and 2), the question also arises as whether this normalisation should be done on raw signal (at $10 \mathrm{~Hz}$ ) or on averaged signals at $5 \mathrm{~min}$. These two aspects were evaluated in the supplementary material $\mathbf{S 2}$ by expressing $\chi_{i, d}$ as a function of $\chi_{i}$ and $c p s_{\mathrm{i}}$ and differentiating eqns. (1), (2) and (5). The full expression was derived as a function of water vapour flux and $\mathrm{H}_{3} \mathrm{O}^{+}$covariance (Eq. S11). We found out that these corrections remained small in this study: lower than $2 \%$ each for $75 \%$ of the time. Only for a few compounds, the corrections attained $10 \%$ for $15 \%$ of the time. These included noticeably acetone. We finally derived the eddy covariance fluxes, by neglecting the water vapour dilution terms and normalising by $\mathrm{H}_{3} \mathrm{O}^{+}$after covariance computation, using the following formula:

$F_{i}=S_{i} \cdot \frac{p_{a}}{R T_{a}} \cdot \frac{1.657 e^{-11} \mathrm{U}_{\text {drift }} \mathrm{T}_{\text {drift }}^{2}}{\mathrm{k}_{\mathrm{drift}}^{2}} \cdot \frac{\mathrm{TR}_{\mathrm{H}_{3} 0^{+}}}{\mathrm{TR}_{\mathrm{R}_{\mathrm{i}} \mathrm{H}^{+}}\left(c p s_{\mathrm{H}_{3} 0^{+}}^{\text {trans }} c p s_{\mathrm{H}_{2} \mathrm{O}_{3} \mathrm{H}^{+}}^{\text {trans }}\right)} \cdot \overline{w^{\prime} c p s^{\prime}}$ 


\subsubsection{High frequency losses}

The magnitude of high frequency losses were evaluated as the difference between the cross-spectrum of the first water cluster and air temperature in the high frequency domain, based on the methodology of (Ammann et al., 2006). High frequency losses could not be computed for VOC due to a too high noise-to-signal ratio, which made the high frequency part of the spectrum non-exploitable for computing the high frequency losses. The loss of signal was starting at a frequency around $0.2 \mathrm{~Hz}$, and the signal was halved at around $2 \mathrm{~Hz}$ (Figure S5). Since the powerspectral frequency was at around $0.2 \mathrm{~Hz}$ at around $14 \mathrm{~h}$ UTC, the high frequency loss appears just after the spectral peak during the day, but the decrease was gentle until $2 \mathrm{~Hz}$ and most of the signal energy was contained below $2 \mathrm{~Hz}$. The high frequency losses evaluated by comparing the co-ogives for water vapour cluster and air temperatures was less than $5 \%$. They were hence not corrected for in the following.

\subsubsection{Fluxes limit of detection and VOC flux selection}

The fluxes limit of detection $\left(\mathrm{LOD}_{\mathrm{f}}\right)$ was determined as the random uncertainty of the eddy covariance method for each compound, which was calculated as the standard deviation of the $\left(w^{\prime}, c^{\prime}\right)$ covariance function at $+80 \mathrm{~s}$ and $-80 \mathrm{~s}$ as described by Wienhold (1994) and Spirig et al. (2005). We chose 80 seconds since our base measurement period was 5 minutes, as opposed to Spirig et al. (2005) who used $180 \mathrm{~s}$ with a base measurement period of $30 \mathrm{~min}$. This choice should make no difference, since the turbulence decorrelation time at the measurement height is much shorter than $80 \mathrm{~s}$. The VOC compounds selected for further analysis were those showing an average flux larger than three times the averaged $\operatorname{LOD}_{\mathrm{f}}$ over the entire duration of the experiment. Note that the average $\mathrm{LOD}_{\mathrm{f}}$ was calculated as the square root of the sum of the squared individual $\mathrm{LOD}_{\mathrm{f}}$ divided by the number of records, to be representative of the error on the mean, as detailed in Langford et al. (2015).

\subsubsection{Identification of VOC, fragments, clusters and isotopes}

Since the PTRMS only measured a mass to charge ratio $\mathrm{m} / \mathrm{z}$, VOC were not strictly identified but tentative raw formula and identification were given based on the closest ion mass and literature (Yáñez-Serrano et al., 2021). Tentative identification are given in Table S2. By further analysing the correlations between ion peaks, we identified possible fragments and clusters belonging to the same compound. Ions having a Spearman correlation coefficient larger than 0.99 were considered belonging to the same compounds. Correlated compounds were mostly identified as isotopes or compounds having $\mathrm{m} / \mathrm{z}$ peaks too close to each other to be separated by the instrument resolution, but also as compounds with a difference in mass between 12 and 42 (Table S3a, b and c).

\subsection{Other measurements}

\subsubsection{Meteorological data and $\mathrm{CO}_{2}$ and energy fluxes from ICOS measurements}

Meteorological measurements were performed in accordance with the protocols required for a level 2 station of

the ICOS ecosystem network. These measurements included wind speed, air and soil temperatures and humidity as well as rainfall, global, net and photosynthetic active radiation. A vertical profile of air temperature and wind speed was measured with 5 two-dimensional ultrasonic anemometers (Wind Sonic, GILL, UK) and shielded thermocouples (HMP155, Vaisala, Finland) placed at 0.5, 1.0, 2.0, 3.0 and $5.0 \mathrm{~m}$ above the ground. The $\mathrm{CO}_{2}$ and $\mathrm{H}_{2} \mathrm{O}$ ecosystem fluxes were measured by Eddy-Covariance, in accordance with the protocols required by the ICOS network. A closed-path $\mathrm{CO}_{2} / \mathrm{H}_{2} \mathrm{O}$ IRGA analyser (Li-7200, LICOR, USA) was placed at $0.2 \mathrm{~m}$ lateral distance 
from an ultrasonic anemometer (HS-50, Gill, UK) to measure the sensible (H) and latent heat (LE) and $\mathrm{CO}_{2}$ fluxes. The high-frequency signals were recorded at $20 \mathrm{~Hz}$ by homemade Labview ${ }^{\circledR}$ program and the fluxes were computed with EddyPro (version 6.2, LICOR, USA). All flux measurements were made on a mast at $2.7 \mathrm{~m}$ height near the centre of the field (Fig. 1) and averaged, and standard deviations were reported over 30 minutes intervals.

\subsection{3 $\mathrm{CH}_{4}$ and $\mathrm{H}_{2} \mathrm{O}$ mixing ratios and fluxes}

$\mathrm{CH}_{4}$ and $\mathrm{H}_{2} \mathrm{O}$ mixing ratios were monitored using a quantum cascade laser (CW-QC-TILDAS76-CS Model, Aerodyne Inc., USA) at $10 \mathrm{~Hz}$. The analyser precision at one second was $2 \mathrm{ppb}$ for $\mathrm{CH}_{4}$ and $\mathrm{XX} \mathrm{ppb}$ for $\mathrm{H}_{2} \mathrm{O}$. The analyser was sampling directly in the Eddy-Covariance line at a flow rate of $7 \mathrm{NL} \mathrm{min}^{-1}$ and pressure $230 \mathrm{mbar}$ below atmospheric pressure. The analyser provided the mixing ratios of $\mathrm{CH}_{4}$ and $\mathrm{H}_{2} \mathrm{O}$, which allowed computing the mixing ratio per mol of dry air at the sampling frequency and calculating the eddy covariance flux with eq. (5) The lag time varied between 2.0 and $2.3 \mathrm{~s}$ for the three compounds similar to what was obtained for the PTR- QiTOF-MS. The QCL was calibrated prior to the experiment.

\subsection{Footprint model and contribution of local flux to mixing ratios}

The FIDES concentration and flux footprint model (Flux Interpretation by Dispersion and ExchangeS) was used to evaluate the flux footprint and to infer the contribution of the VOC fluxes to the VOC concentration measured at the site (Carozzi et al., 2013; Loubet et al., 2018; Loubet et al., 2010). The model is based on the same analytical solution of the advection-diffusion equation as the Korman-Meixner model (Kormann and Meixner, 2001), All details of the model can be found in (Loubet et al., 2018).

\subsection{Dataset and statistical analysis}

All data were merged to a common data frame according to their date and time and averaged at hourly time steps. A dataset was generated for each ion peak. The dataset is available as an R object in the supplementary material. All statistics were performed under $\mathrm{R}$ ( $\mathrm{R}$ version 4.0.1, 2020-06-06).

\section{Results}

\subsection{Meteorological conditions, crop development, $\mathrm{CO}_{2}$ and energy fluxes}

305 The experiment took place after wheat anthesis, during the grain-filling period (Ripening stage, Figure 3). During that period, the grain was progressively filled up to reach a biomass of around $500 \mathrm{~g} \mathrm{DW} \mathrm{m}^{-2}$, similar to the stems biomass (Figure 3). The senescence also started at the beginning of that period which showed an increase of the yellow-to-green leaves biomass ratio. The crop height was around 0.8-1.0 $\mathrm{m}$ height. 

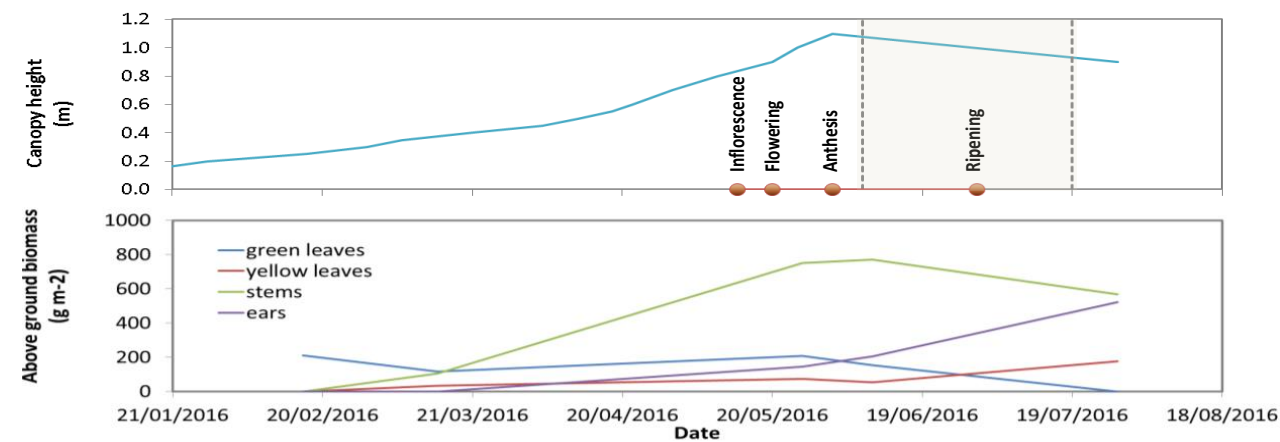

310 Figure 3. Top: crop height and crop developmental stages. The experimental period is shown in grey shading. Bottom: evolution of the above ground biomass of different plant compartments.

The campaign started a week after a major flooding event in the Parisian area characterised by a three week lasting rain period that might have affected the crop functioning, although the $\mathrm{CO}_{2}$ flux was in the range of expected fluxes for a wheat crop at that period. The main wind direction was west-south-west, the wind speed $1.8 \mathrm{~m} \mathrm{~s}^{-1} \mathrm{on}$ average with a typical daily pattern showing night-time low wind speeds except for a few short windy periods (1113, 20-21 and 28-31 June), accompanied by lower temperatures, higher relative humidity and consistent precipitations (Figure 4). Air temperature was $17.7^{\circ} \mathrm{C}$ on average and varied from 8 to $31^{\circ} \mathrm{C}$ with hot periods around 27 June, and 7 and 17 July. The period from 12 to 23 June was quite wet, while the driest periods were from 7 to 12 June and from 4 to 11 July. The albedo decreased slightly from 0.23 at the start of the experiment (around anthesis) to 0.18 on June 23 (grain filling period) and remained stable afterward. The air temperature at the crop roughness height $\mathrm{z}_{0}\left(T_{z_{0}}\right)$, which is a proxy for the plant surface temperature varied from $10^{\circ} \mathrm{C}$ to $45^{\circ} \mathrm{C}$. The highest temperatures were observed towards the end of the campaign where at mid-day $T_{z 0}$ was exceeding the air temperature by up to $10^{\circ} \mathrm{C}$. Before that period, the air-to-canopy temperature difference did not exceed $5^{\circ} \mathrm{C}$ at mid-day. The soil temperature (at $5 \mathrm{~cm}$ ) followed the air temperature pattern but with daytime maxima lower than air temperature by 5 to 15 degrees and night temperature slightly higher than air temperatures due to the canopy shading. The heatwave at the end of the period corresponded to very high water vapour pressure deficits at $T_{\mathrm{z} 0}$ (larger than $4 \mathrm{kPa}$ ), while it was usually smaller than $2 \mathrm{kPa}$ before. Night periods usually exhibited dew formation except towards the end of the campaign. 

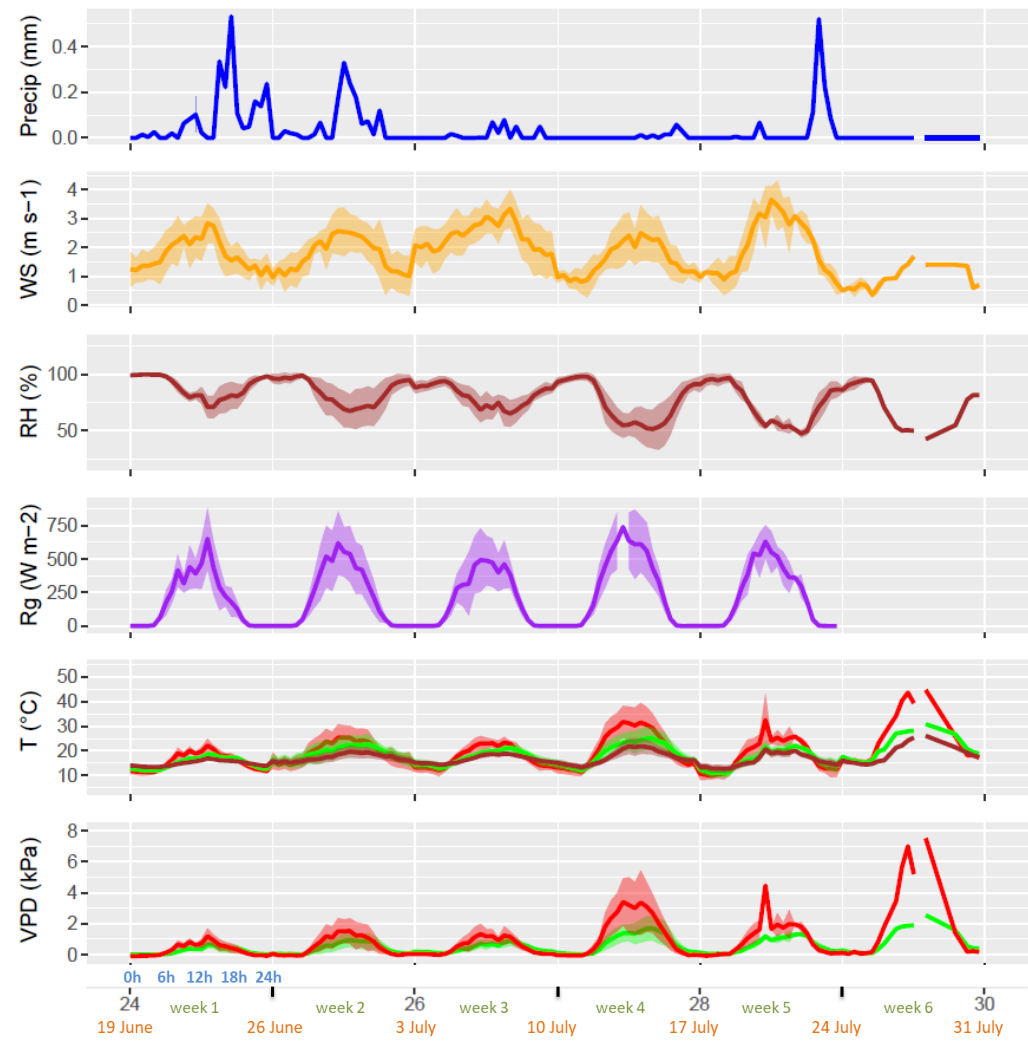

Figure 4a. Meteorological conditions at the site during the experiment at the reference height measured by eth ICOS FR-GRI station. Precipitation (P), wind speed (WS), relative humidity (RH), solar incoming radiation (Rg), air (green), crop (red) and soil ( $5 \mathrm{~cm}$ depth, brown) temperatures, vapour pressure deficit of the air (green) and the leaf surface vapour pressure deficit VPD(Tz0, red), and dew occurrence potential (dew) as estimated with negative periods of VPD(Tz0). Each week shows the diel cycle with its mean (line) and standard deviation (ribbons). The $x$-axis shows the week number in the year (black) and over the experiment (green), starting date of the week (orange), hour of day (blue).

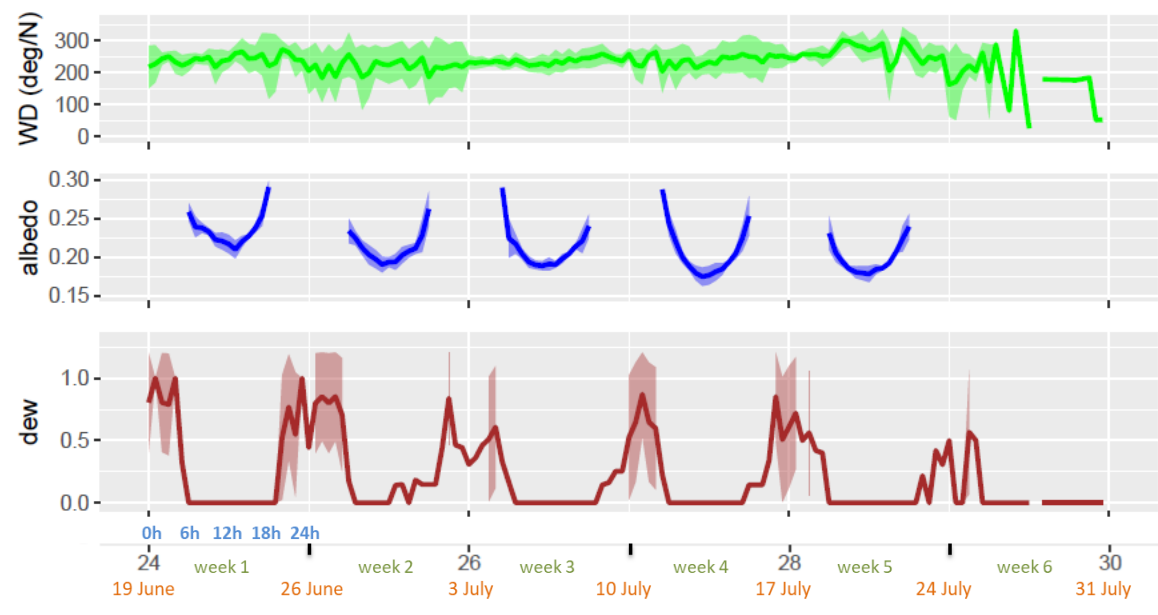


Figure 4b. Meteorological conditions, continued. Wind direction (WD), albedo and wetness index (dew, $1=$ surfaces fully covered by water, $0=$ dry surfaces). Each week shows the diel cycle with its mean (line) and standard deviation (ribbons). The $x$-axis shows the week number in the year (black) and over the experiment (green), starting date of the week (orange), hour of day (blue).

The typical friction velocity of the site was around $0.3 \mathrm{~m} \mathrm{~s}^{-1}$ though quite large during the windy periods (2nd to the $4^{\text {th }}$ week), where it reached $0.5 \mathrm{~m} \mathrm{~s}^{-1}$ (Figure 5). The exchange velocity for water vapour $V_{\max }\left(\mathrm{H}_{2} \mathrm{O}\right)$, which is the physical limitation for convective exchanges, varied daily and showed maximum exchange rates of $3 \mathrm{~cm} \mathrm{~s}^{-1}$ at mid-day and minimum values at night near zero except during the windy periods. The $\mathrm{CO}_{2}$ fluxes showed net absorption during daytime at the beginning of the experiment. They were fairly constant until June 15 and then began to decline until July 5 (first senescence phase), when they switched to net daytime respiration (second senescence phase). Water vapour fluxes exhibited a lower decrease during the same period and showed a high correlation with net radiation but less to vapour pressure deficit. This indicated that although the canopy was absorbing less $\mathrm{CO}_{2}$, it was still transpiring, and hence the stomata were opened. After week 3, the water vapour flux was rather constant which indicates that at that time the crop was fully senescent and stomata were not responding to light anymore. Because of the decrease of evaporation, and under quite large net radiations, the sensible heat flux increased from the 20 June onward, while the ground heat fluxes daily variations sharply increased after the 5 July. The flux footprint from the main field was mostly above 0.8 (median 0.86 , interquartile 0.76 - 0.91 ) but showed some consistent periods with a lower footprint (down to 0.4) when the wind was blowing from the south. The periods with a footprint lower than 0.6 occupied $13 \%$ of the time. 

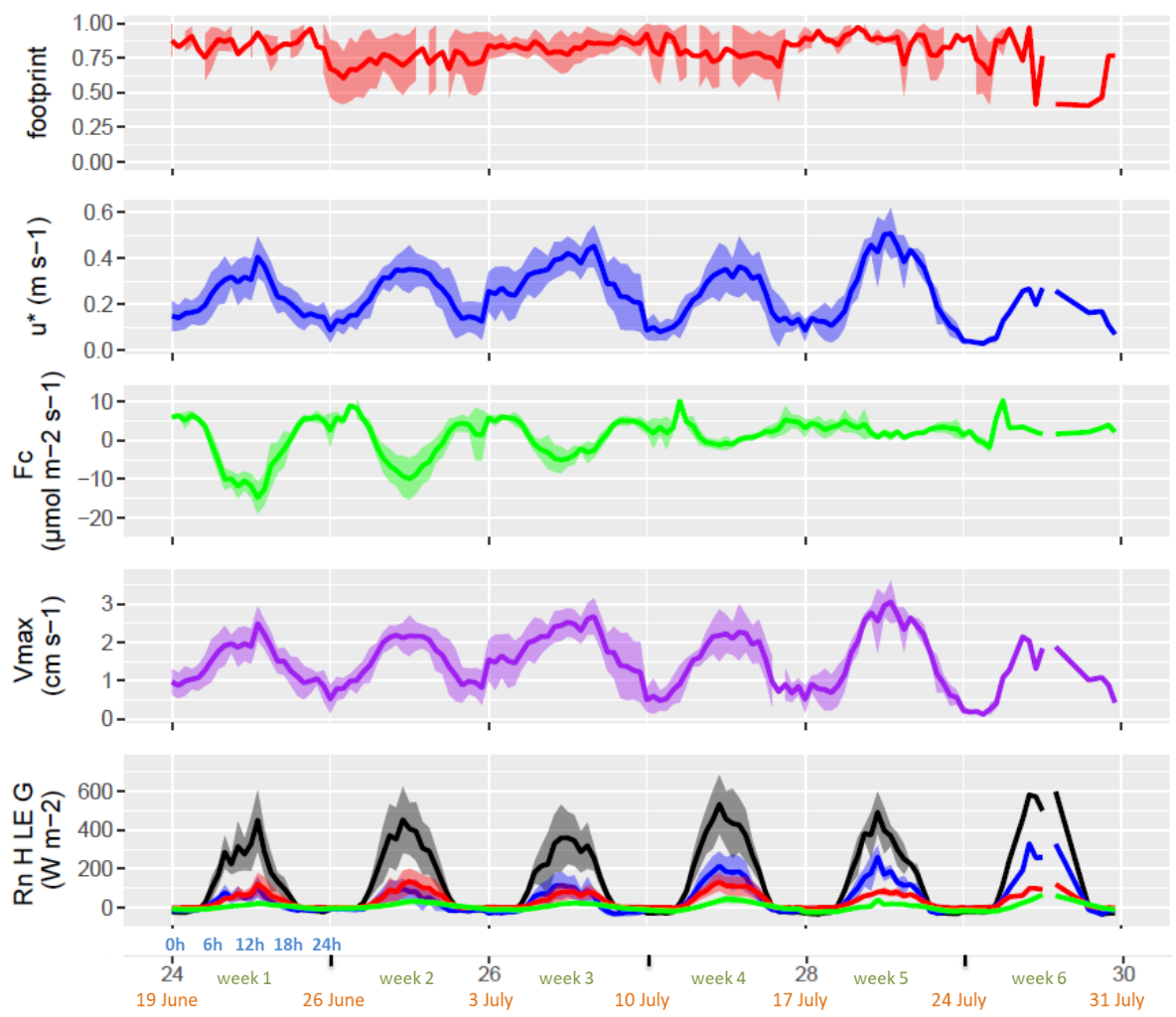

Figure 5. Footprint, friction velocity $\left(u^{*}\right), \mathrm{CO}_{2}$ flux $(\mathrm{Fc})$, maximum exchange velocity for water $(\mathrm{Vmax})$, and the terms of heat balance (Rn H LE G): the net radiation (Rn, black), sensible heat flux (H, blue), latent heat flux (LE, red) and ground heat flux (G, green). By convention, except for $\mathrm{Rn}$ and $\mathrm{G}$, positive fluxes are lost by the ecosystem and negative fluxes are gained/taken up by it. Each week shows the diel cycle with its mean (line) and standard deviation (ribbons). The $x$-axis shows the week number in the year (black) and over the experiment (green), starting date of the week (orange), hour of day (blue).

\subsection{VOC mixing ratios}

The most concentrated VOC at the site were methanol, acetone, $\mathrm{C} 6 \mathrm{H} 4 \mathrm{O}$, propanoic acid, ketene, propyne, acetaldehyde, formaldehyde, and hydrazine acetate (Table S2). The mixing ratios of most emitted and deposited VOC showed no marked daily patterns but some similarities in their weekly patterns (Figure 6). The first week of the experiment showed smaller mixing ratios and diurnal variations than the rest of the experimental period. This period corresponded to a rainy period with westerly winds typical of oceanic influence at the site (Figure 4). The second week showed an increase in the mixing ratios of all compounds that mostly lasted for 3 weeks. This period corresponded to the end of the rainy period, a sudden change of the wind direction to the east (direction of Paris megacity), and an increase in temperature and water vapour content of the atmosphere (Figure 4). This event also brought polluted air masses from the Parisian area as shown by the increase in $\mathrm{NO}_{2}$ (Figure S15). Compounds like DMS (m/z 63.026) showed a sharp increase following rain stop, which dropped quickly. Phenols (m/z 95.049) mixing ratios showed a similar behaviour although they stayed larger for a longer period. 


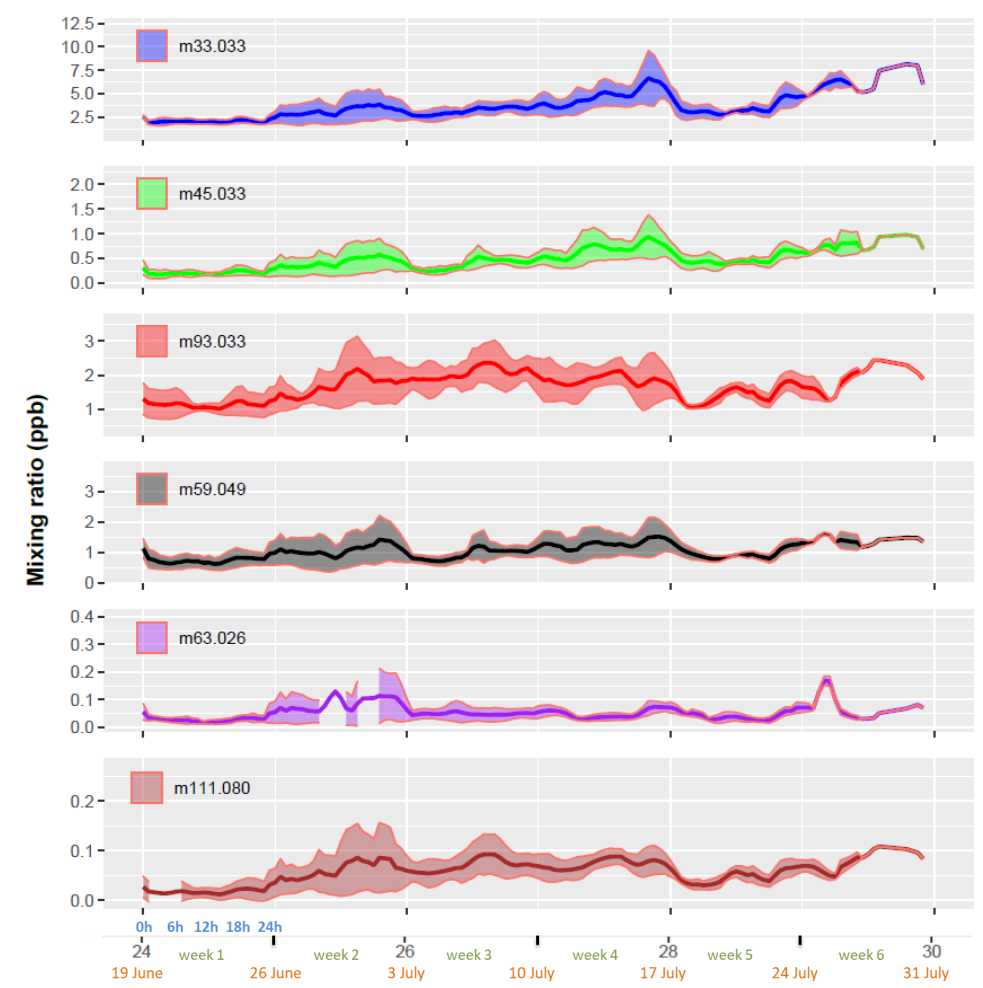

Figure 6a. Mixing ratios at $2.7 \mathrm{~m}$ above ground of the six most emitted VOC.

This period also showed an increase of some oxygenated compounds that were mostly depositing ( $\mathrm{m} / \mathrm{z} 101.060$,

$\mathrm{m} / \mathrm{z}$ 83.049) (Table S2). Week 3 corresponds to the windy period mentioned in Figure 5 with a well-mixed boundary layer both during day and night, and to wind blowing from the farm. The following week is marked by the highest concentrations of methanol and acetaldehyde but also of some deposited compounds $(\mathrm{m} / \mathrm{z} 75.044$, but also 145.968 and $\mathrm{m} / \mathrm{z} 54.947$ noticeably). This period corresponded to high air temperatures (up to $30^{\circ} \mathrm{C}$ ) and high surface temperatures (up to $40^{\circ} \mathrm{C}$ ) (Figure 4). This is also noticeably the period when the crop stopped photosynthesising (Figure 5) and hence the end of the senescence period, although the high water vapour fluxes suggests that stomata were still opened. The period also showed the highest $\mathrm{O}_{3}$ and $\mathrm{NO}$ mixing ratios, due to the first weekend of the summer holidays in France and a huge traffic rush in the Region (Figure S15). Finally, the last week corresponded to a very warm period with low wind-speeds. Overall we see that the change in E/N the 29 June affected only marginally the mixing ratios. 

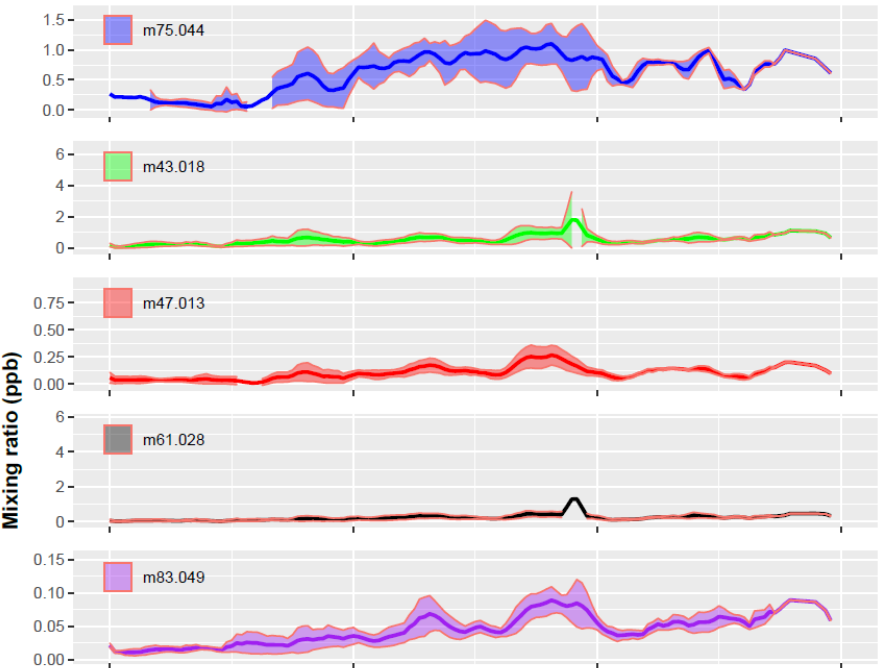

Figure 6b. Mixing ratios at $2.7 \mathrm{~m}$ above ground of the six most deposited VOC.

\subsection{VOC fluxes}

Overall, 264 VOC showed fluxes larger than three times the flux limit of detection $\left(\operatorname{LOD}_{\mathrm{f}}\right)$ when computed over the whole period. However, when expressed over hourly periods, only four VOC showed an averaged flux larger than the mean of LODf. This explicates the fact that over long integration periods, the $\mathrm{LOD}_{\mathrm{f}}$ diminishes because it is essentially a random error. Over these 264 VOC, 77 were on averaged emitted while 187 were on averaged deposited.

The most emitted compound was methanol ( $\mathrm{m} / \mathrm{z} 33.033)$, emitted at a molar rate of $0.5 \mathrm{nmol} \mathrm{m}^{-2} \mathrm{~s}^{-1}$ on average, which was about 6 times larger than the next most emitted compound $\mathrm{m} / \mathrm{z}$ 93.033, identified as $\mathrm{C}_{6} \mathrm{H}_{4} \mathrm{O}$ (Figure 7, Table S2). Acetaldehyde ( $\mathrm{m} / \mathrm{z}$ 45.0433) was the third most emitted compound, while acetone ( $\mathrm{m} / \mathrm{z} 59.049)$ was the fourth emitted compound and dimethyl sulfide (DMS, m/z 63.026) the fifth. Methanol emissions increased from the first to the fourth week, decreased during the $5^{\text {th }}$ week and were large again during the last week of July. The daily pattern showed a maximum at around $12-15 \mathrm{~h}$ and a negative minimum at the end of the night. Both daily and weekly patterns suggest a clear dependency to temperature and wetness. Ion $\mathrm{m} / \mathrm{z} 93.033$ showed a different seasonal pattern with largest emissions during the second week, and then decreasing emissions towards the end of July, suggesting less dependency to temperature. Acetaldehyde showed a similar trend as methanol, suggesting a source linked to a similar process. Acetone showed a rather stable daily pattern during the period, except for a slightly larger flux during week 4. DMS showed a peak emission at the end of the rain period (middle of the second week) and a decrease afterward. DMS also showed a slight increase during the hottest period. 


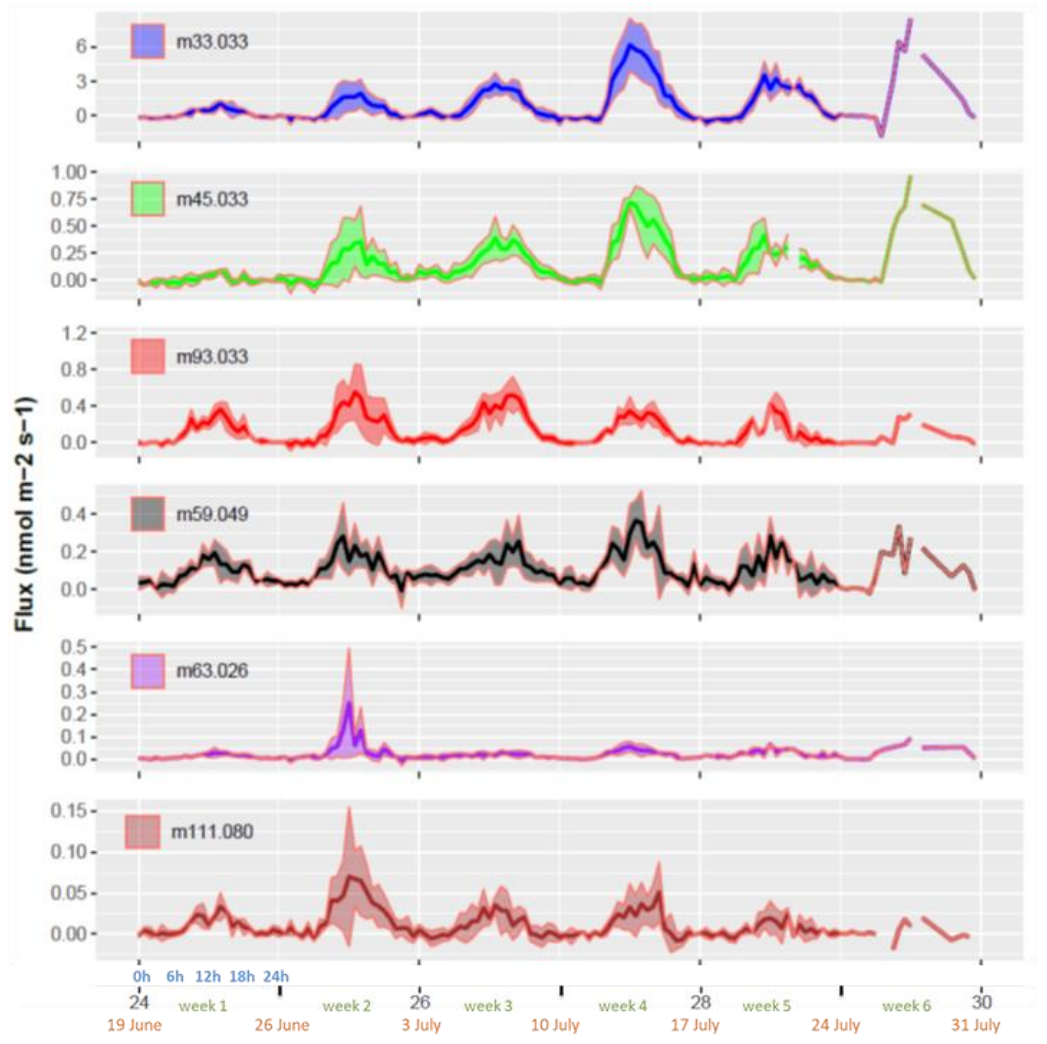

Figure 7. Whole ecosystem fluxes of the six most emitted VOC. Each week shows the diel cycle with its mean (line) and standard deviation (ribbons). The $x$-axis shows the week number in the year (black) and over the experiment (green), starting date of the week (orange), hour of day (blue).

The most deposited compounds were hydroxyacetone (m/z 75.044), ion $\mathrm{m} / \mathrm{z} 43.018$ (which comprises fragments of several oxygenated compounds), formic acid (m/z 47.013), acetic acid (m/z 61.028), formaldehyde (m/z 31.018), methylfuran and MBO (m/z 83.049) (Figure 8). These compounds contributed to $15 \%, 14 \%, 9 \%, 8 \%$, $5 \%$ and $4 \%$ of the deposition fluxes summed over all compounds that passed the $\mathrm{LOD}_{\mathrm{f}}$ criteria, on a molar basis, respectively. The VOC depositing showed distinct patterns: m/z 75.044 (hydroxyacetone) was deposited consistently throughout the period with larger deposition during weeks 2 to 4 , mirroring the emission behaviour of $\mathrm{m} / \mathrm{z}$ 93.033. Ion ( $\mathrm{m} / \mathrm{z} 43.018)$ and acetic acid ( $\mathrm{m} / \mathrm{z}$ 61.028) showed a similar pattern of bi-directional fluxes with small depositions or even emissions during the first two weeks, large depositions during week 3 , then reducing towards small emissions during the last weeks. Butene (m/z 57.070) and cyclopentane (m/z 71.085) showed a similar pattern as the formic and acetic acids (data not shown). Formic acid (m/z 47.013) and methylfuran/MBO $(\mathrm{m} / \mathrm{z}$ 83.049) showed a similar deposition pattern with a small deposition during the first two weeks followed by an increase in week 3, a maximum in week 4 and a decrease during week 5 . On the contrary, formaldehyde $(\mathrm{m} / \mathrm{z}$ 31.018) showed a consistently larger deposition rate during the first two weeks, followed by a decrease in deposition in the following weeks, switching to a net emission during the $5^{\text {th }}$ week. 

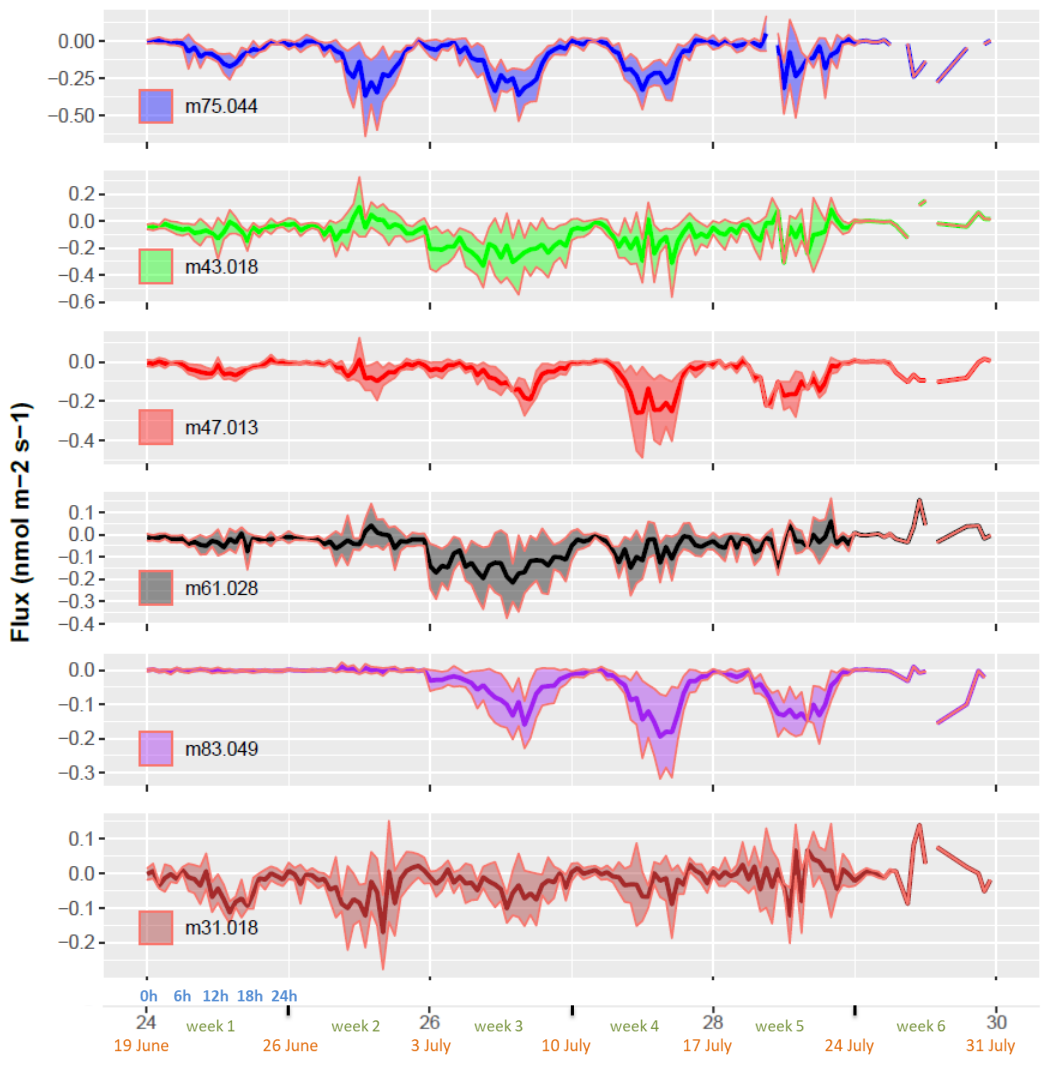

Figure 8. Whole ecosystem fluxes of the six most deposited VOC. Each week shows the diel cycle with its mean (line) and standard deviation (ribbons). The $x$-axis shows the week number in the year (black) and over the experiment (green), starting date of the week (orange), hour of day (blue). See Table 2 for the list of compounds corresponding to these ions.

\subsection{Summed emissions and deposition}

The averaged emissions summed over all VOC amounted $0.85 \pm 0.05 \mathrm{nmol} \mathrm{m}^{-2} \mathrm{~s}^{-1}$ (where the uncertainty is the sum of all LODf). This corresponded to $36 \mathrm{~g} \mathrm{ha}^{-1} \mathrm{day}^{-1}\left(\sim 18 \mathrm{~g} \mathrm{Cha}^{-1} \mathrm{day}^{-1}\right)$. Methanol contributed to $62 \%$ of the summed VOC emissions on a molar basis, while $\mathrm{m} / \mathrm{z} 93.033$ and acetaldehyde contributed around $11 \%$ and $9 \%$, respectively, DMS contributed to $1.6 \%$. The averaged summed depositions amounted $0.38 \pm 0.08 \mathrm{nmol} \mathrm{m}^{-2} \mathrm{~s}^{-1}$, which corresponded to $27 \mathrm{~g} \mathrm{ha}^{-1}$ day $^{-1}\left(\sim 12 \mathrm{~g} \mathrm{C}^{-1} \mathrm{day}^{-1}\right)$. Interestingly, the summed VOC depositions was $43 \%$ of the summed emissions on a molar basis, but was around $73 \%$ when expressed on a mass basis. This shows that the deposited compounds were on average heavier than the emitted ones. Additionally, the daily pattern of deposition fluxes showed two peaks, the latter one probably corresponding to a rush hour, suggesting a dominant traffic source for these compounds. However the first peak was rather around noon, suggesting a biological or chemical source (Figure 9). Overall, the summed emissions and depositions led to a net emission of $\sim 10 \pm 2.6 \mathrm{~g} \mathrm{ha}^{-1}$ day $^{-1}\left(\sim 6.7 \pm 1.8 \mathrm{~g} \mathrm{C}^{-1}\right.$ day $\left.^{-1}\right)$. 

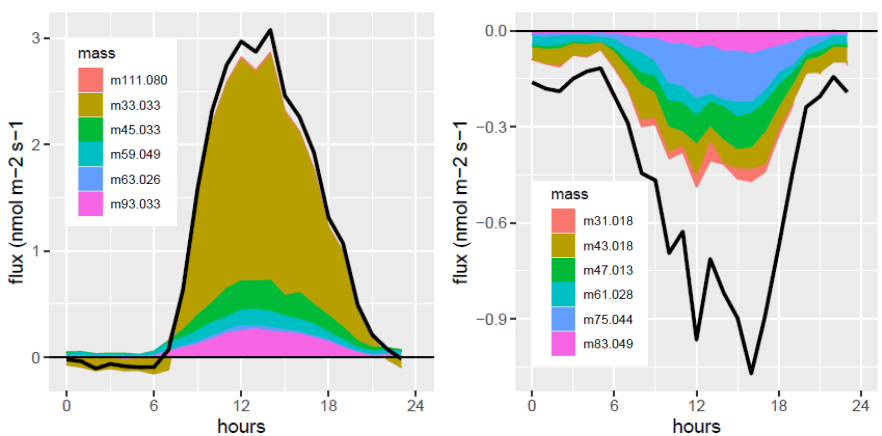

Figure 9. Stacked daily averaged for the 6-most emitted (left) and 6-most deposited (right) VOC. Black lines show summed-up emissions and depositions for compounds with fluxes larger than LODf.

\section{Discussion}

\subsection{Flux measurements with a PTR-Qi-TOF-MS}

Because of the air density fluctuations, the Webb Penman Leuning (WPL) corrections needs to be applied on the eddy covariance flux (Webb et al., 1980). This correction accounts for dilution by water vapour and temperature induced density variations. Because of the long and heated sampling lines and large thermal mass of the drift tube, temperature variations can be neglected. Water vapour dilution however needs to be accounted for, since the water vapour fluctuations are not directly measured in the PTRMS. Eq. (S9) shows the WPL correction specific to the PTR-TOF-MS. We confirmed that this correction was most of the time smaller than a few percent (Figure S1), because of the small mixing ratio of the measured VOC in environmental conditions.

Another issue that, to our knowledge, was not discussed before concerns the effect of normalising the cps by the cps of $\mathrm{H}_{3} \mathrm{O}^{+}$on $10 \mathrm{~Hz}$ data prior to calculating the eddy covariance fluxes. We showed that the bias is a function of the $\mathrm{cps}_{\mathrm{H} 3 \mathrm{O}+}$ covariance which is not null since $\mathrm{H}_{3} \mathrm{O}^{+}$are consumed by VOCs and water vapour that are themselves correlated to vertical wind speed (Eq. S13 and S14). We showed that the bias introduced is however small and negligible when integrated over time (Figure S2 and S3). To avoid any unwanted bias it is however recommended to calculate covariances based on raw cps and normalised the covariance by the primary ion afterwards $\mathrm{H}_{3} \mathrm{O}^{+}$.

High frequency losses were evaluated to be small and in line with the expected values for the lag time of our sampling system (lower than 5\%) (Ammann et al., 2006). These high frequency losses were evaluated based on the first water cluster (m/z 37.028, Figure S5). Based on the comparison of the shapes of the cross-correlation functions for the water cluster and methanol (Figure S4), we hypothesise that the high frequency losses for methanol should be similar to that for water vapour. Since methanol is a sticky compound, we expect that this would be also true for most measured VOC. We however did not manage to evaluate the high frequency losses based on the cross-spectra for methanol, since it showed some higher values at high frequencies than at lower ones (Figure S5). We interpret this as an effect of the noise-to-signal ratio of the VOC cps (Langford et al., 2015). Although we expected some large noise contribution to the variance of the VOC signals, we did not expect a contribution to the w.cps cross-spectra. The cross-spectra exemplified in Figure S5 however show the opposite. A reconstruction of the a noisy signal mimicking that of methanol confirms that noisy signals are difficult to 
analyse for high frequency losses since the high frequency end of the signal is dominated by the noise. To tackle this issue, one would need to develop some denoising algorithm, which is beyond the scope of this manuscript. Overall, we were able to identify more than 260 VOC that had fluxes larger than three times the flux limit of detection (LODf). This is smaller than Park et al. (2013a) who reported almost 500 VOC which fluxes were above three times the LODf. This is not fully surprising since they measured above an orange orchard in the Central Valley of California in the summer, which is much more emitting ecosystem (Park et al., 2013b). Indeed, they found a methanol flux ( $73 \mu \mathrm{g} \mathrm{C} \mathrm{m}^{-2} \mathrm{~h}^{-1}$ ) around three times larger than in this study ( $\left.23 \mu \mathrm{g} \mathrm{C} \mathrm{m}^{-2} \mathrm{~h}^{-1}\right)$, and similarly for acetone and acetaldehyde. Overall, their fluxes were hence at least three times larger than ours, which probably explains the larger number of compounds having a flux above the LODf in their study. Interestingly however we found around the same number of depositing compounds ( 190) (Park et al., 2013a).

\subsection{Most emitted compounds and comparison with existing literature}

Methanol (m/z 33.033). In their global methane budget, Jacob et al. (2005) estimated that growing vegetation is the major source of methanol $\left(128 \mathrm{Tg} \mathrm{yr}^{-1}\right)$ followed by recombination of methylperoxyradicals $\left(\mathrm{CH}_{3} \mathrm{O}_{2}\right)$ with itself and other organic peroxy radicals $\left(38 \mathrm{Tg} \mathrm{yr}^{-1}\right)$, plant decay $\left(23 \mathrm{Tg} \mathrm{yr}^{-1}\right)$, biomass burning and biofuels (13 $\mathrm{Tg}$

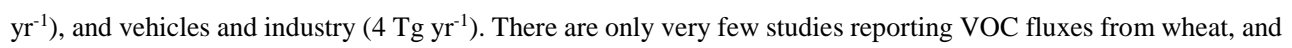
only one from whole wheat canopy (Table 1). All existing studies have shown that methanol is the most emitted compound by wheat with contributions ranging between 20 and $80 \%$ depending on the study site, measurement method and scale, weather conditions and phenological stage (Bachy et al., 2020; Gonzaga Gomez et al., 2019). We found methanol fluxes remarkably comparable to (Bachy et al., 2020), giving strength to these estimations. In terms of temporal dynamics, our study shows an emission increase towards senescence (Figure 7), with a maximum emission coinciding with the end of the chlorosis period and the decline of photosynthesis (Figure 5). An increase of methanol emissions during senescence was also observed at the canopy scale by Bachy et al. (2020) on wheat and at the leaf scale by Mozaffar et al. (2018) on maize, and Gonzaga et al. (2020, submitted). These observations suggest that cereal crops are a major source of methanol at the end of culture cycle with net emission rates possibly exceeding those during the vegetative growth phase. This may be explained by several processes: (1) Demethylation of pectin occurs also during aging and senescence of plant tissues as shown by Michele et al. (1995), or (2) a pronounced degradation of cellular constituents at the end of chlorosis (Keskitalo et al., 2005; Woo et al., 2019), which both promote methanol production and its release through higher leaf porosity. In addition, temperature is an important factor influencing methanol emissions by increasing methanol permeability at higher temperature, due to structural changes of the cell membranes, and by increasing enzyme activity. Thus methanol emissions depend on temperature during all stages of development including senescence, although they are associated with transpiration, and hence depend on stomatal conductance also (Harley et al., 2007). Since wheat senescence occurs in a much warmer period than the growth period, it promotes larger emissions during that period, as well illustrated here. Increased methanol emissions have been reported above cut grasslands (Seco et al., 2007), which may suggest a similar process as during wheat senescence.

515 Bachy et al. (2018) have further shown that soil may be a significant methanol source, which may be promoted by crop residues and high temperatures during the summer. However, methanol is also absorbed by bacteria and fungi, and used as a substrate for their growth (Chaignaud et al., 2018; Morawe et al., 2017). Hence net methanol flux over soil may be a combination of emission by organic matter decomposition and microorganism consumption. 
Finally, methanol as a very soluble compound, can also be readily adsorbed in water layers present in the canopy and desorbed when the canopy dries out, as shown by Laffineur et al. (2012) over a mixed temperate forest and confirmed by Bachy et al. (2018) over maize. Zhou et al. (2017) showed that $80 \%$ of the emitted methanol in a boreal forest was dry deposited. In our study, we found rather small deposition rates during nighttime (Figure 7), with the highest deposition rate at the end of the night, corresponding to conditions when canopy was the wettest (Klemm et al., 2002). This small deposition is however probably a net combination of some night-time emission and deposition as explained in Zhou et al. (2017). The same possibly happened during the day after rainfall.

$\mathbf{m} / \mathbf{z}$ 93.033. Emissions of $\mathrm{m} / \mathrm{z} 93.033$, tentatively identified as $\mathrm{C}_{6} \mathrm{H}_{4} \mathrm{O}$, were not reported for crops so far, apart from the work of Gonzaga et al. (2019) using the same instrument at the same site. The whole canopy scale measurements in this study and the plant chamber measurements by Gonzaga-Gomez et al. (2019) revealed similar flux magnitudes for these compounds (Table 1). Both studies observed maximum fluxes during the grain-filling period, which showed large $\mathrm{CO}_{2}$ assimilation (Figure 5). To our knowledge, the only references reporting emissions of this compound are from an orange orchard (Park et al., 2013b), biomass burning (Stockwell, 2016) and root endophytic fungi (Serendipita) (Venneman et al., 2020) studies, but also Gonzaga et al. (2019) who found emissions of $\mathrm{m} / \mathrm{z} 93.033$ from oilseed rape plants. Park et al. (2013b) report an average flux of $4.2 \mu \mathrm{g} \mathrm{C} \mathrm{m}^{-2} \mathrm{~h}^{-1}$ over $24 \mathrm{~h}$, which is twice as low as the emissions reported here, when the measured three times larger methanol emissions. Hence, the ratio of $\mathrm{m} / \mathrm{z} 93.33$ to $\mathrm{m} / \mathrm{z} 33.033$ would be around six.

Acetaldehyde (m/z 45.033) was the third most emitted compound with a flux range similar to what was reported in previous studies over wheat (Table 1), although at a much larger average rate than that reported by Bachy et al. (2020). This may be explained by the fact that averaged over the entire season while our measurements were focused on the period between grain filling and senescence, which shows the highest seasonal emissions of acetaldehyde. The measurements from Gonzaga et al. (2019) in a nearby field with dynamic chambers shows remarkable agreement during the grain-filling period. As pointed out by Gonzaga et al. (2019), measurements with quad-PTRMS may have led to miss-interpretation of acetaldehyde as $\mathrm{CO}_{2} \cdot \mathrm{H}^{+}$, a potential yet not characterised bias in the studies using these instruments. The emission pattern of acetaldehyde was very similar to that of methanol, suggesting a similar production process leading to emissions, or at least a similar dependency of these processes to environmental conditions and plant and soil physiology (Figure 5 and 7). However, the mechanisms leading to acetaldehyde emissions are not well characterised yet, especially in the field. Three main routes have been proposed: (1) leaf wounding, as for instance reported by De Gouw et al. (2000) with acetaldehyde emissions after wounding of wheat averaging $15 \%$ of that of methanol, or Graus et al. (2011) for maize; (2) light-dark transition which leads to temporary cytosolic pyruvate accumulation in leaves and subsequent decarboxylation that may produce acetaldehyde (Karl et al., 2002); and (3) exposure to oxidative (ozone) and anoxic stresses (Seco et al., 2007). Regarding this latest process, several studies on water treatment by ozonation have shown that organic matter oxidation is a source of acetaldehyde. Our site was indeed shown to have substantial ozone fluxes with a large fraction entering the stomata $\left(10 \mathrm{~kg} \mathrm{ha}^{-1} \mathrm{y}^{-1}\right)$ (Potier et al., 2015). Furthermore, Potier et al. (2017) have further shown that ozone reacts strongly with wheat leaf water extracts and especially for senescent wheat. They have found several VOC dissolved in leaf water extract, which may explain the high reactivity of ozone with leaf extracts. Studies on water treatment by ozonation have further shown that organic matter oxidation is a source of acetaldehyde (Papageorgiou et al., 2014). This suggests that a possible acetaldehyde emission route from crops may be through oxidation of organic matter in the apoplasm or bulk plant or soil organic matter. This route would 
especially be important during senescence when the cells degrade and organic matter is exposed to the atmosphere.

This hypothesis is also compatible with VOC emissions reported by Zhao et al.(2016) just after wheat straw application.

Acetone (m/z 59.049). Acetone is also mostly emitted by terrestrial vegetation ( $\sim 30 \%$ of the total emissions) and oceans ( $30 \%)$, with additional sources being plant decay (2-10\%) and oxidation of isoalkanes in the atmosphere (Jacob et al., 2002). Acetone was the fourth most emitted compound in this study. In the literature, acetone. Bachy et al. (2020) found acetone to behave very similarly to acetaldehyde with deposition mostly observed during the early stages of the cropping season (which is also the wettest and coldest period), and emissions increasing throughout senescence and ranking second to third most emitted compound. Gonzaga et al. (2019) reported acetone to be the second-most emitted compound by wheat, oilseed rape and maize plants. Maillard reactions in dead decaying plant material was identified as a potential important source of acetone to the atmosphere (Warneke et al., 1999). Acetone emissions are also caused by plant stress such as injury (Davison et al., 2008), ozone and water logging (Cojocariu et al., 2005). As discussed for acetaldehyde, ozonolysis of epicuticular waxes may also be a mechanism for the production of acetone at the plant surfaces (Fruekilde et al., 1998). The available literature, therefore, suggests that acetone emissions by plants may significantly come from non-enzymatic reactions occurring during degradation of plant cells and surfaces, although acetone may also be a secondary product of the cyanogenic pathway (Seco et al., 2007). Soil may also be a source of acetone, which increased with soil organic matter (Abis et al., 2018; Schade and Goldstein, 2001; Zhao et al., 2016). 
Table 1. Fluxes and mixing ratios of the $\mathbf{1 0}$ most emitted VOC found in this study, together with isoprene and monoterpenes, compared to measurements reported over wheat in the literature.

\begin{tabular}{|c|c|c|c|c|c|c|}
\hline \multirow{2}{*}{$\mathbf{m} / \mathbf{z}$} & \multirow{2}{*}{$\begin{array}{c}\text { Tentative } \\
\text { identification }\end{array}$} & \multirow{2}{*}{$\begin{array}{c}\text { Mixing } \\
\text { ratio } \\
\text { ppb }\end{array}$} & \multicolumn{2}{|l|}{ Flux } & \multirow{2}{*}{$\begin{array}{l}\text { Measurement } \\
\text { method }\end{array}$} & \multirow{2}{*}{ Reference } \\
\hline & & & $\mu \mathrm{g} \mathrm{m}^{-2} \mathbf{h}^{-1}$ & $n g g^{-1} D W h^{-1}$ & & \\
\hline \multirow[t]{3}{*}{33.033} & Methanol & 2.6 & $63 \pm 4$ & $\sim 30 \pm 2$ & Eddy covariance & this study \\
\hline & & & & $680-1100$ & Dynamic chamber & G2019 \\
\hline & & $1-10$ & $62 \pm 3.3[-459-1128]$ & $-255-710$ & Eddy covariance & B2020 \\
\hline \multirow[t]{2}{*}{93.037} & $\mathrm{C}_{6} \mathrm{H}_{4} \mathrm{O}$ & 3.7 & $32 \pm 1.6$ & $\sim 15 \pm 1$ & Eddy covariance & this study \\
\hline & & & & $10-50$ & Dynamic chamber & G2019 \\
\hline \multirow[t]{3}{*}{45.033} & Acetaldehyde & 1.2 & $13 \pm 0.8$ & $\sim 7 \pm 0.4$ & Eddy covariance & this study \\
\hline & & & & $10-50$ & Dynamic chamber & G2019 \\
\hline & & & $-2 \pm 0.8[-148-135]$ & $-80-75$ & Eddy covariance & B2020 \\
\hline \multirow[t]{3}{*}{59.049} & Acetone & 2.1 & $14 \pm 0.5$ & $\sim 7 \pm 0.3$ & Eddy covariance & this study \\
\hline & & & & $80-180$ & Dynamic chamber & G2019 \\
\hline & & & $-2 \pm 0.8[-135-135]$ & $-75-75$ & Eddy covariance & В2020 \\
\hline \multirow[t]{2}{*}{63.026} & DMS & 0.1 & $3.1 \pm 0.2$ & $\sim 1.6 \pm 0.1$ & Eddy covariance & this study \\
\hline & & & $0-11.6$ & $0-14.5$ & Closed chamber & K1995 \\
\hline 95.049 & Phenols & 0.4 & $2.3 \pm 0.2$ & $\sim 1.2 \pm 0.1$ & Eddy covariance & this study \\
\hline 111.080 & $\begin{array}{l}\text { 3-Cyclohexene-1- } \\
\text { carboxaldehyde }\end{array}$ & 0.2 & $3.1 \pm 0.2$ & $\sim 1.6 \pm 0.1$ & Eddy covariance & this study \\
\hline 113.015 & $\mathrm{C}_{5} \mathrm{H}_{4} \mathrm{O}_{3}$ & 0.1 & $2.5 \pm 0.2$ & $\sim 1.3 \pm 0.1$ & Eddy covariance & this study \\
\hline 47.049 & $\begin{array}{l}\text { Ethanol or dimethyl } \\
\text { ether }\end{array}$ & 0.1 & $0.9 \pm 0.2$ & $\sim 0.5 \pm 0.1$ & Eddy covariance & this study \\
\hline \multirow[t]{6}{*}{69.070} & Isoprene + fragments & 0.4 & $-1.1 \pm 0.2$ & $\sim 0.6 \pm 0.1$ & Eddy covariance & this study \\
\hline & From m/z 68.06 ${ }^{\#}$ & $0.1-0.2$ & $2.4-4.8$ & $\sim 1.2-2.4$ & Eddy covariance & this study \\
\hline & & & & $-5-110$ & Dynamic chamber & G2019 \\
\hline & & & 4.8 & $0-6000$ & Dynamic chamber & M2016 \\
\hline & & & $-10-25^{*}$ & $-5.5-14$ & Eddy covariance & B2020 \\
\hline & & & & $0-50$ & Dynamic chamber & K2009 \\
\hline \multirow[t]{4}{*}{137.132} & Monoterpenes & & $-0.8 \pm 0.1$ & $\sim 0.5 \pm 0.05$ & Eddy covariance & this study \\
\hline & & & & $-50-18$ & Dynamic chamber & G2019 \\
\hline & & & $0-12000$ & $0-420000$ & Dynamic chamber & M2016 \\
\hline & & & $-10-25^{*}$ & $-5.5-14$ & Eddy covariance & B2020 \\
\hline
\end{tabular}

K1995 (Konig et al., 1995). K2009 (Karl et al., 2009a). B2020 (Bachy et al., 2020). G2019: (Gonzaga Gomez et al., 2019). M2016 (Morrison et al., 2016). K1995 (KANDA et al., 1995). In this study, $18 \mathrm{~T} \mathrm{ha}^{-1}$ dry biomass, which is the mature wheat field biomass, was used as a scaling parameter. K1995: closed chamber measurements were performed over 10 minutes twice a day in PVC chambers. * Rough estimations based on averaged diurnal cycles. Mean \pm se $[5-95$ percentiles] and max $-\min$. ${ }^{\#} \mathrm{~m} / \mathrm{z} 68.06$ which C5H8+ is used as proxy. It is multiplied by 12 to 24 , which is the slope of $\mathrm{m} / \mathrm{z} 69.07$ to $\mathrm{m} / \mathrm{z} 68.06$ at $\mathrm{E} / \mathrm{N}=150$ and $\mathrm{E} / \mathrm{N}=130$ respectively.

Dimethyl sulphide (DMS, $\mathbf{m} / \mathbf{z}$ 63.026). DMS was the fifth most emitted compound in our study. Our results are in very good agreement with those from Kanda et al. (1995) who measured DMS emissions from maize and wheat with closed chambers, a technique which may however be criticised for exposing the plants to unnatural, nonsteady state environmental conditions (Niinemets et al., 2011). Kanda et al. (1995) clearly showed that the above ground part of the wheat was the source. However, there is little other evidence of DMS emissions from terrestrial plants. Yonemura et al. (2005) found emissions only from Hibiscus spec. in quantities comparable to our studies $\left(\sim 6 \mu \mathrm{g} \mathrm{m}^{-2} \mathrm{~h}^{-1}\right)$. Jardine et al. (2015) reported large DMS concentrations in the Amazon forest, and showed that a 
soil source was present. Very recently, Vettikkat et al. (2020) reported large emissions of DMS by tropical forest trees (Mahogany tree, Swietenia macrophylla) in the range of 1-6 $\mu \mathrm{g} \mathrm{m}^{-2}$ (of leaf) $\mathrm{h}^{-1}$ ), which can be converted to 7-40 $\mathrm{g} \mathrm{m} \mathrm{m}^{-2} \mathrm{~h}^{-1}$ assuming a LAI of $\sim 7 \mathrm{~m}^{2} \mathrm{~m}^{-2}$ observed in the present study. However, globally, the largest identified DMS sources so far are oceans, through dimethylsulphoniopropionate (DMSP) production by phytoplankton in their photosynthetic cycle (GROENE, 1995). The global marine DMS source was estimated as $28 \mathrm{Tg} \mathrm{S} \mathrm{yr}^{-1}$, which is a 100 times larger than terrestrial emissions (0.3 $\left.\mathrm{Tg} \mathrm{S} \mathrm{yr}^{-1}\right)$ (Kloster et al., 2006). In terms of fluxes, these emissions correspond to an average $\sim 13 \mu \mathrm{g} \mathrm{m}^{-2} \mathrm{~h}^{-1}$ over the total ocean area, which is larger than the average flux we found in this study for wheat. This confirm that terrestrial emissions are much lower than oceanic ones, since cultivated surfaces represent only $\sim 4 \%$ of the oceanic surfaces. In terms of emissions processes, DMSP does not seem to be so common in terrestrial plants. Nevertheless, DMSP was found to be emitted from several species, and to increase under drought stress in Arundo donax (Haworth et al., 2017). We noticeably found larger DMS emissions during the second week (Figure 7), which corresponded to a period with a consistently larger atmospheric water vapour concentration and some rain. This suggests that DMS emissions in wheat may be promoted by wet conditions. However, Gonzaga-Gomez et al. (2019) did not found DMS to be emitted by wheat leaves in amounts similar to our study, suggesting an emission rather from the soil. Carrión (2017) suggested soil emissions by methanethiol degradation by soil bacteria. Abis et al. (2018) found indeed emissions from sieved soils, though small in magnitude. Furthermore, Venneman et al. (2020) showed clear emissions of DMS from root endophytic Serendipita fungi. Clearly, DMS emissions by terrestrial ecosystems, and soils in particular should be investigated further.

Isoprene (m/z 69.070). Crops are low emitters of isoprenoids (Lathière et al., 2010). In our study, m/z 69.070 was mostly depositing, except during the first week (Figure 7). Bachy et al. (2020) also reported deposition events, especially during senescence in the early morning. Since isoprene is fragmenting and other compounds fragment on $\mathrm{m} / \mathrm{z} 69.070$, the observed deposition of $\mathrm{m} / \mathrm{z} 69.070$ may be due to other compounds than isoprene (Karl et al., 2012; Zhou et al., 2017). This issue is discussed in the supplementary material (Figure S9). Assuming that $\mathrm{m} / \mathrm{z}$ $68.050\left(\mathrm{C}_{5} \mathrm{H}_{8}{ }^{+}\right)$may be used as a proxy of isoprene, it mostly showed emissions except for week 28 , suggesting that isoprene may be emitted by the wheat but MBO and other fragmenting compounds would be mostly depositing. Based on that assumption, and bearing in mind that it is a hypothesis, we evaluated that isoprene was mostly emitted at a rate close to Morisson et al. (2016) and similar to Bachy et al. (2020) (Table 1).

Monoterpenes (m/z 137.129). MT fluxes were mostly downward (Table 2), with a flux range of fluxes similar to that of Bachy et al. (2020) reported. We found that the cps of ions $\mathrm{m} / \mathrm{z} 81.070$ and 137.129 were highly correlated (correlation coefficient $=0.98$ ), with a ratio 81/137 of 2.5 (Table S3), in agreement with previous studies (Misztal et al., 2012; Steeghs et al., 2007; Tani et al., 2004; Tani et al., 2003). This ratio and the correlation coefficient were stable whatever the $\mathrm{E} / \mathrm{N}$, though slightly higher at $\mathrm{E} / \mathrm{N}=150(2.7)$. However, interestingly the $\mathrm{m} / \mathrm{z} 137.129$ deposition flux was larger than that of $\mathrm{m} / \mathrm{z} 81.070$, while the mixing ratios were oppositely ranked. This indicates that the MTs consisted of a mix of compounds having different deposition velocities and different fragmentation patterns. Indeed the ratio of $\mathrm{m} / \mathrm{z}$ 81/137 was shown to depend on the MT compound and E/N (Misztal et al., 2012). According to their study, and bearing in mind the many uncertainties, the measured ratio 81/137 in our study would correspond to 3-carene. Deposition of monoterpenes was observed over grassland by (Bamberger et al., 2011) over grassland during an episode when the surrounding pine forest was damaged by a hailstorm, hence showing that Monoterpenes can be deposited when ambient concentration is large. In our study, the site was next to a woodland 
and in addition the nearby farm was a source of monoterpenes (Kammer et al., 2020), that clearly enhanced the mixing ratios of MT under favourable wind conditions. (Figure S10). This suggests MT deposition was induced by local advection from surrounding sources. Deposition of monoterpenes was also demonstrated by modelling studies even for canopies that were small MT emitters, confirming a bi-directional behaviour of MT fluxes (Zhou et al., 2017).

Phenols ( $\mathbf{m} / \mathbf{z}$ 95.049). Phenol emissions from terrestrial surfaces are mostly due to biomass burning but also to fresh manure and livestock (Kammer et al., 2020). Phenol is common in decomposing organic material. However, we have found no data on phenol emissions from plants or soils. The experimental field receives a lot of manure and slurry (Loubet et al., 2011). This organic matter, together with the senescing plants may hence contribute to the overall phenol emissions. Phenolic compounds, and especially phenol-propanoids and benzenoids is a class present in all plants and essentially produced via the shikimate pathways from amino acids (Fares et al., 2010), and in wheat noticeably (Kiraly, 1962), and could lead to phenol emissions when plant tissues decompose.

\subsection{Most depositing VOC}

Most of the compounds that were measured as depositing were tentatively identified as oxygenated VOC. The most depositing compound was $\mathbf{m} / \mathbf{z} \mathbf{7 5 . 0 4 4}$, which was tentatively identified as hydroxyacetone $\left(\mathrm{C}_{3} \mathrm{H}_{6} \mathrm{O}_{2}\right)$ (Table 2). Hydroxyacetone (HAC) is an oxidation product of isoprene after oxidation by $\mathrm{O}_{3}$, $\mathrm{OH}$ or NO. High deposition velocities above a forest averaging $1.4 \mathrm{~cm} \mathrm{~s}^{-1}$ have been reported by Nguyen et al. (2015). In our study deposition velocity of HAC was about 20 times lower, which can be partly explained by the lower turbulences above a wheat crop with respect to a forest canopy, leading to higher transfer resistances Seinfeld, 1998 \#23380\}. We evaluate that in our study the maximum exchange velocity $\left(V_{\max }\right)$, which expresses the maximum deposition velocity for a non-reactive compound, was 3 to 4 times lower than in Nguyen et al. (2015). We are not aware of other studies reporting hydroxyacetone deposition over crops. In terms of carbon, HAC deposition represented about $1 / 3$ of the methanol emission and was 3 times the isoprene emissions (Table 1). Regarding its diurnal variation, the deposition velocity showed a very clear pattern with an increase early in the morning, a quite constant $V_{\mathrm{d}}$ throughout the day, and a decrease late in the evening (Figure 10). Nguyen et al. (2015) found a similar increase in the morning but a decrease that started earlier during the day and became enhanced towards the evening. The difference between these studies may suggest a difference in the non-stomatal deposition or in the daily turbulence pattern between studies. Products of atmospheric VOC oxidation like HAC can be taken up by plants and metabolized as shown for example by Karl et al. (2010).

The second most deposited ion was $\mathbf{m} / \mathbf{z} 43.018$ (Table 2). Although the raw formula of this ion is quite clear $\left(\mathrm{C}_{2} \mathrm{H}_{2} \mathrm{O} . \mathrm{H}^{+}\right)$and would correspond to ethenone, it is most certainly a mix of several fragments (2,3 butanedione, acrylic acid, methyl vinyl ketone, acetic acid, formic acid), as shown by the synthesis of Yáñez-Serrano (2021)). In particular, it was shown to be a fragment of acetic acid by Baasandorj et al. (2015). We indeed found a correlation of 0.9 between $\mathrm{m} / \mathrm{z} 61.028$ and $\mathrm{m} / \mathrm{z} 43.018 \mathrm{cps}$ and observed a clear correlation between the two ion fluxes (Figure 8). We also found a correlation of 0.84 between $\mathrm{m} / \mathrm{z} 71.049$ (MVK and MACR) and m/z 43.018 cps. Ion $\mathrm{m} / \mathrm{z} 43.018$ did not show very clear diel deposition velocity pattern. However, during the stormy third week, the deposition flux and velocity increased in magnitude (Figure 8 and 10). The absence of clear daily pattern in deposition velocity is surprising since $V_{\max }$ itself shows a diel pattern. This may be related to a surface resistance that compensates the daily variations in $V_{\max }$, namely higher surface resistance during the day and lower ones at 
nights due to the affinity with water of these compounds that are mostly polar. Indeed, at night leaves surfaces were often wet while they were dry during the day, as shown by the wetness index (Figure 4b). Ion $\mathrm{m} / \mathrm{z} 43.018$ was also emitted during a short dry period at the start of the senescence, but no emissions, nor strong deposition were observed when the canopy was either growing of completely senescent. This bi-directional behaviour may be due to the fact that this ion is a combination of several compounds.

Table 2. Fluxes and mixing ratios of the six most depositing VOC found in this study, compared to measurements reported in the literature over any type of vegetation.

\begin{tabular}{|c|c|c|c|c|c|c|}
\hline $\mathbf{m} / \mathbf{z}$ & $\begin{array}{c}\text { Tentative } \\
\text { Raw } \\
\text { formula }\end{array}$ & $\begin{array}{c}\text { Tentative } \\
\text { identification }\end{array}$ & $\begin{array}{c}\text { Mixing ratio } \\
\text { ppt }\end{array}$ & $\begin{array}{c}\text { Flux } \\
\text { nmol } \mathbf{m}^{-2} \mathbf{s}^{-1}\end{array}$ & $\begin{array}{c}\text { Vdep } \\
\mathrm{mm} \mathrm{s}^{-1} \\
\end{array}$ & Ref. \\
\hline \multirow[t]{2}{*}{75.044} & \multirow[t]{2}{*}{$\mathrm{C} 3 \mathrm{H} 6 \mathrm{O} 2$} & \multirow{2}{*}{$\begin{array}{c}\text { Hydroxyacetone } \\
\text { (HAC) }\end{array}$} & $590[2-1400]$ & $-0.06[-0.23-0.02]$ & $0.1[-0.04-0.4]$ & This study \\
\hline & & & {$[50-1300]$} & $-0.2[-0.6-0.05]$ & $1.4 \pm 0.5[0-2]$ & N2015 \\
\hline 43.018 & $\mathrm{C} 2 \mathrm{H} 2 \mathrm{O}$ & $\begin{array}{c}\text { Fragments }^{1} \\
\text { Ethenone }\end{array}$ & $510[50-1200]$ & $-0.05[-0.22-0.06]$ & $0.13[-0.1-0.5]$ & This study \\
\hline \multirow[t]{2}{*}{61.028} & \multirow[t]{2}{*}{$\mathrm{C} 2 \mathrm{H} 4 \mathrm{O} 2$} & \multirow[t]{2}{*}{ Acetic acid } & \multirow[t]{2}{*}{$220[0-540]$} & \multirow[t]{2}{*}{$-0.03[-0.14-0.03]$} & \multirow[t]{2}{*}{$0.16[-0.2-0.7]$} & This study \\
\hline & & & & & & R2011 \\
\hline 83.049 & C5H6O & Methylfuran & $40[9-90]$ & $-0.02[-0.10-0.01]$ & $0.03[-1.0-1.0]$ & This study \\
\hline 47.013 & $\mathrm{CH} 2 \mathrm{O} 2$ & Formic acid & $120[0-330]$ & $-0.03[-0.13-0.01]$ & $0.31[-0.4-1.2]$ & This study \\
\hline \multirow[t]{2}{*}{101.059} & \multirow[t]{2}{*}{$\mathrm{C} 5 \mathrm{H} 8 \mathrm{O} 2$} & \multirow{2}{*}{$\begin{array}{l}\text { 4-oxopentanal } \\
\text { Pentenoic acid }\end{array}$} & \multirow[t]{2}{*}{$20[3-60]$} & \multirow[t]{2}{*}{$-0.01[-0.06-0.01]$} & \multirow[t]{2}{*}{$0.26[-0.6-1.6]$} & This study \\
\hline & & & & & & R2011 \\
\hline
\end{tabular}
(both $\mathrm{C}_{4} \mathrm{H}_{6} \mathrm{O}, \mathrm{m} / \mathrm{z}$ 71.049), acetic acid. See Yáñez-Serrano (2021). N2015: (Nguyen et al., 2015). Ranges were estimated from Figure S17. R2011: (Ruuskanen et al., 2011). Values under brackets are min and max. K1998 : Kesselmeier et al. (1998). Fluxes were measured over barley and expressed per leaf area index. They were multiplied by the maximum are index observed in this study $\left(7 \mathrm{~m}^{2} \mathrm{~m}^{-2}\right)$, to transform to comparable units. Value under brackets are standard deviations

$\mathbf{m} / \mathbf{z} 61.028$ (tentatively attributed to acetic acid) was the third most depositing compound. Acetic acid is formed in the atmosphere by oxidation of isoprene, and its oxidation products, with $\mathrm{O}_{3}$ and $\mathrm{OH}$ at low $\mathrm{NO}$ (Link et al., 2020). However acetic acid can be directly emitted from soils (Mielnik et al., 2018), and from plants especially under stress conditions and during senescence (Portillo-Estrada et al., 2020). Kesselmeier et al. (1998) found emissions of acetic acid from trees but only deposition on barley and other crops, suggesting a bi-directional stomatal uptake and subsequent usage by plant metabolism. In a follow-up study, Staudt et al. (2000) confirmed a bi-directional behaviour, showing that the foliar exchanges of acetic acid (and formic acid) are light dependent with emission predominantly occurring by day and deposition by night. In particular, they showed that the emissions are highest in the morning and progressively decrease during the course of the day. As evidenced for other oxygenated VOC, acetic acid partitions strongly into the aqueous phases inside the plant tissues and accumulate during night time when stomata are closed and transpiration is minimal (Niinemets et al., 2014). Once stomata open in the morning, large amounts of water soluble VOC are emitted with the onset of transpiration, but subsequently decline due to the depletion of their pools. In the present study, however, an opposite behaviour was observed, where acetic acid deposition velocity showed slightly largest $V_{\mathrm{d}}$ in the morning than during the afternoon

(Figure 10). This behaviour may reflect the presence of dew in the wheat canopy and at the soil surface that remains there during the morning, where acetic acid would be efficiently trapped. It may also be due to an afternoon source of acetic acid from the plant metabolism or soil that would partially compensate its deposition. Acid emission was indeed shown to increase with temperature (Filella et al., 2007) and transpiration (Kesselmeier et 
al., 1998). The mechanism of turgor regulation could also influence the acid emissions during the day by reducing the $\mathrm{pH}$ levels in the apoplasm therefore increasing the gaseous to aqueous ratio of acids, thereby favouring their volatilisation (Gabriel et al., 1999).

$\mathbf{m} / \mathbf{z}$ 83.049 $\left(\mathrm{C}_{5} \mathrm{H}_{6} \mathrm{O}\right.$, tentatively attributed to Methylfuran) was the fourth most depositing compound. It also had one of the highest deposition velocity in our study. Little can be found in the literature about fluxes of this compound, but is a very well know oxidation product of isoprene (Karl et al., 2009b). Helmig et al. (1998) report Methylfuran mixing ratios of $90 \mathrm{ppt}$ near the ground and $80 \mathrm{ppt}$ throughout the whole boundary layer over a tropical forest, suggesting a near-ground source in this environment. Methylfuran is known to be formed primarily during combustion processes, and is detected in biomass burning plumes (Hatch et al., 2017; Koss et al., 2018 ). In this study the deposition velocity showed a marked diurnal cycle with a maximum around 14h (UTC) and a minimum at night (Figure 10). A strong increase in $\mathrm{m} / \mathrm{z} 83.049$ deposition velocity was observed starting on week 3. This suggests a possible link with the senescence of the plant, which started on week 3 (Figure 5). Mixing ratios correlations suggest that at $\mathrm{E} / \mathrm{N}=130$, ion $\mathrm{m} / \mathrm{z} 101.096$ fragmented to $\mathrm{m} / \mathrm{z} 83.049$ (correlation coefficient of 0.96). At $\mathrm{E} / \mathrm{N}=150$ the correlation is less clear, probably because more fragments contribute to $\mathrm{m} / \mathrm{z} 83.049$ leading to lower correlations between ions couples. However, the seasonal pattern and magnitude of $\mathrm{m} / \mathrm{z} 83.049$ were not strongly affected by fragments (see supplementary material). Diurnal and seasonal patterns were similar between $\mathrm{m} / \mathrm{z} 83.049$ and $\mathrm{m} / \mathrm{z} 47.013$ (formic acid) after week 3, suggesting a similar deposition process for the two ions during senescence (Figures 8 and 10). 

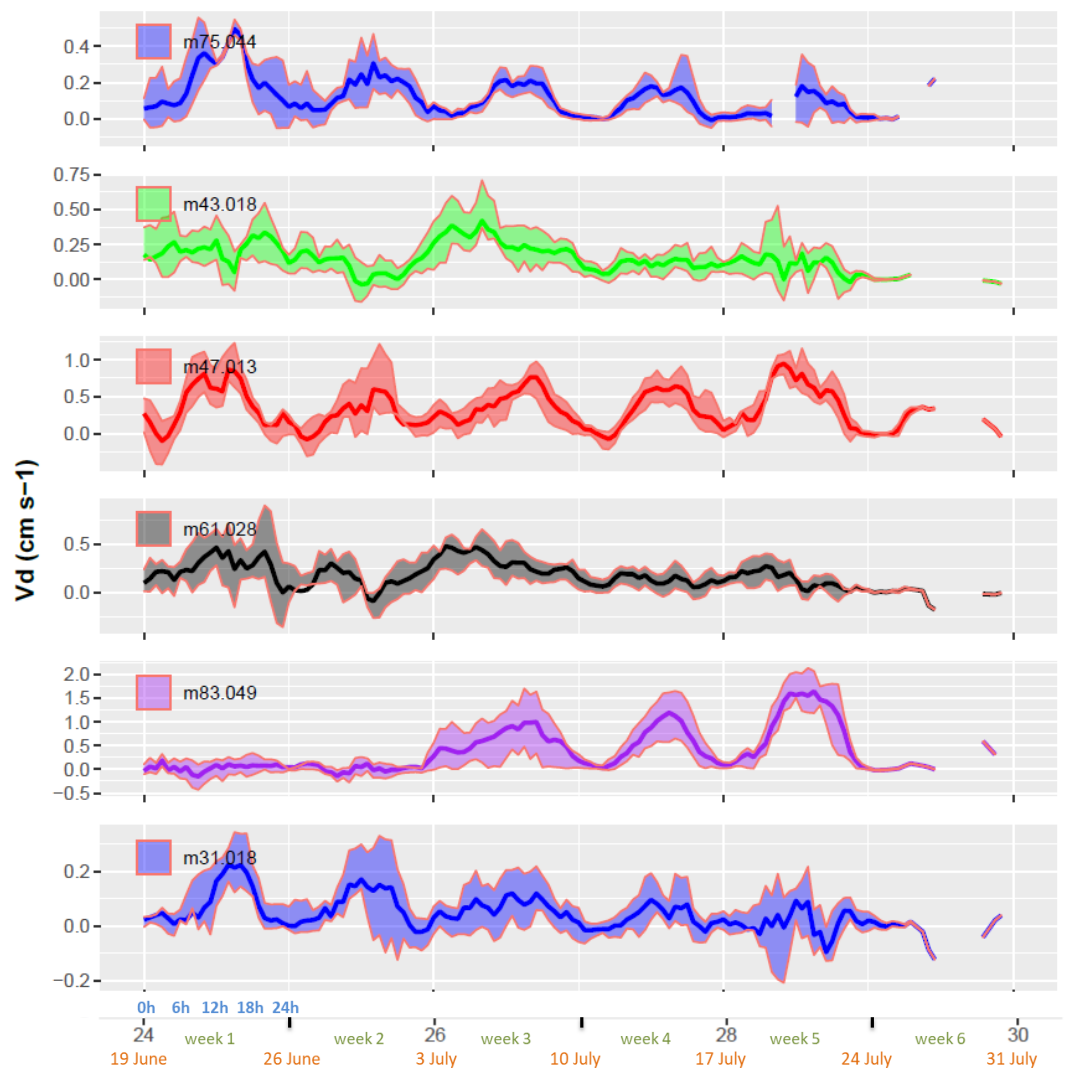

Figure 10. Diurnal cycle of deposition velocity of the six most depositing VOC. The $x$-axis shows the week number in the year (black) and over the experiment (green), starting date of the week (orange), hour of day (blue). Each week shows the diel cycle with its mean (line) and standard deviation (ribbons). See Table 2 for the list of compounds corresponding to these ions.

$\mathbf{m} / \mathbf{z}$ 47.013 (formic acid, $\mathrm{CH}_{2} \mathrm{O}_{2}$ ) was indeed also depositing substantially and had high deposition velocities Link et al. (2020) showed that it is formed from the oxidation of isoprene degradation products (MACR, isoprene epoxydiol, IEPOX, isoprene hydroxy hydroperoxide, ISOPOOH) with the $\mathrm{OH}$ radical. The daily pattern of $V_{\text {dep }}$ showed clear deposition during the day, and the smallest deposition rate at the end of the night. Formic acid is also known to be produced by organic matter degradation (Holopainen et al., 2017), and several studies show clear emissions of formic acid from ecosystems (Nguyen et al., 2015; Rantala et al., 2015). Bi-directional fluxes were indeed reported by Brilli et al. (2016) in a European forest, and by Jardine et al. (2011) in a tropical forest, who further estimated that the compensation point was around $1.3 \mathrm{ppb}$. In our study, we had however smaller atmospheric concentrations suggesting that the compensation point was much smaller (lower than $70 \mathrm{ppt}$ ).

$\mathrm{m} / \mathrm{z} 101.059\left(\mathrm{C}_{5} \mathrm{H}_{8} \mathrm{O}_{2}\right.$, tentatively identified as 4-oxopentanal, 4-OPA or pentenoic acid) was reported to be emitted by pig slurry (Feilberg et al., 2015; Ni et al., 2012), but also from a cow and sheep farm (Hobbs et al., 2004; Kammer et al., 2020), but no deposition was reported previously to our knowledge. Pentenoic acid is also known to play a role in bacteria-fungi interactions in soil (Effmert et al., 2012; Scholler et al., 2002). Jud et al. (2016) observed formation of $\mathrm{C}_{5} \mathrm{H}_{8} \mathrm{O}_{2}$ (identified as 4-oxopentanal) by ozonolysis of plant essential oils or 
diterpenes emitted by plant surfaces, but no deposition was reported. In this study, $\mathrm{C}_{5} \mathrm{H}_{8} \mathrm{O}_{2}$ was behaving very similarly to methylfuran $\left(\mathrm{C}_{5} \mathrm{H}_{8} \mathrm{O}\right)$. Indeed, the cps had a correlation coefficient of 0.95 , and both showed similar deposition velocity patterns with an increase from week 3 onwards, suggesting that the deposition of these compounds was promoted by the senescing state of wheat. Whether the underlying deposition processes may be linked with acetaldehyde emissions that are also enhanced during senescence, (Figure 6) would need further investigations.

\subsection{VOC mixing ratios influenced by the nearby farm}

As the site is on a farm but also in a sub-urban region, the question arises as to whether the observed mixing ratios are comparable to the regional signal or largely influenced by the local environment and especially the farm, the animals and the surrounding fields. Some compounds were clearly identified as coming from the nearby animal farm by analysing the mixing ratio frequency as a function of the wind direction and wind speed (Figure 11, Figure S10-S12, and Table S2). Some of these compounds are those which, according to Kammer et al. (2020), are the most emitted by the farm itself, in particular acetic acid (m/z 61.028), but also monoterpenes (m/z 137.129 and its fragment $\mathrm{m} / \mathrm{z} 81.070)$, as well as $\mathrm{m} / \mathrm{z} 136.000$, identified as a Benzothiazole $\left(\mathrm{C}_{7} \mathrm{H}_{5} \mathrm{~N}_{\mathrm{s}}\right)$. The pollution rose of these compounds showed three typical behaviours shown in Figure 11.
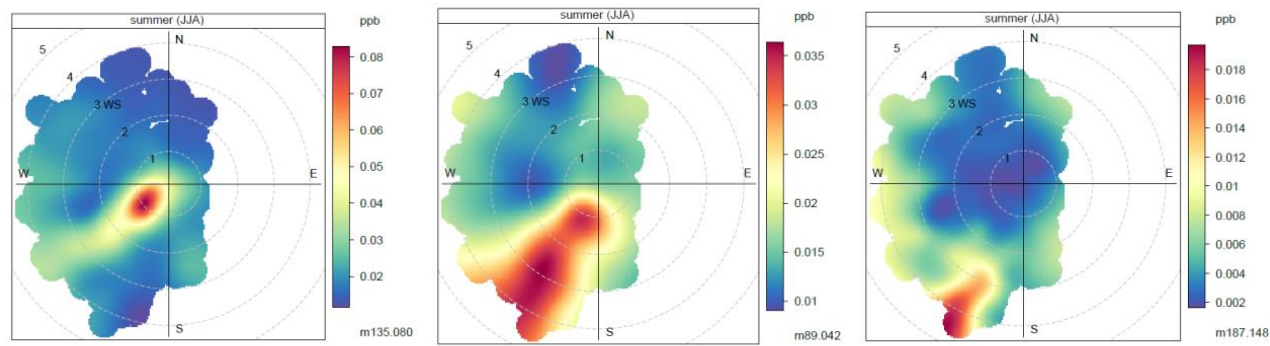

Figure 11. Three typical wind rose of compounds identified as coming from the farm. Colours show the mixing ratios, and plots are binned by averaged wind direction and wind speeds. Left: constantly emitting source (example methane). Middle: source emitting with a daily pattern (example of $\mathrm{C}_{4} \mathrm{H}_{8} \mathrm{O}_{2}$ ). Right: secondary photo-produced compound (example m/z 187.148, possibly $\mathrm{C}_{11} \mathrm{H}_{22} \mathrm{O}_{2}$ )

The first behaviour concerns $\mathrm{m} / \mathrm{z} 135.117$ (tentatively identified as $\mathrm{C}_{10} \mathrm{H}_{14}$ but which may also include some terpenes, like para-cymene) which shows large mixing ratios for a narrow wind sector and low wind speed and is very similar to the methane pollution rose (Figure S9), a tracer of the animal activity. This is typical of a nighttime increase due to a local source that is emitting constantly during the day and night. Indeed, larger wind speeds observed during the day (Figure 4) dilute more the compound, which is hence observed in lower concentrations during the day than at night. Compounds that behave similarly are monoterpenes (m/z 137.129), and an oxygenated monoterpene (m/z 153.127) (Figure S11).

The second behaviour concerns $\mathrm{m} / \mathrm{z} 89.042\left(\mathrm{C}_{4} \mathrm{H}_{8} \mathrm{O}_{2}\right)$, which showed high mixing ratios for a larger wind sector and for both low and high wind speeds. This is a less usual behaviour, which may reflect the fact that for large wind speeds the emission is also larger, hence compensating the turbulent mixing effect. Since wind speed and temperature are correlated with each other throughout the day (Figure 4), we can hypothesize that emissions of this compound may increase with temperature inside the farm, which is influenced by the temperature outside. Indeed this is corroborated by the positive correlation with temperature of the mixing ratios for this compound

(Figure S11). Compounds that behave similarly are acetic acid $(\mathrm{m} / \mathrm{z} 61.028)$ and $\mathrm{m} / \mathrm{z} 103.075\left(\mathrm{C}_{5} \mathrm{H}_{10} \mathrm{O}_{2}\right)$ and 
$\mathrm{m} / \mathrm{z} 117.084\left(\mathrm{C}_{6} \mathrm{H}_{12} \mathrm{O}_{2}\right)$. Interestingly, Kammer et al. (2020) found all these compounds to come from the stable and being linked to the silage feeding operations. Silage is indeed a source of these compounds as well as ethanol, linked to microorganisms activity which increase with temperature

Finally, the third behaviour exemplified by $\mathrm{m} / \mathrm{z} 187.148\left(\mathrm{C}_{14} \mathrm{H}_{18}\right.$ or $\left.\mathrm{C}_{11} \mathrm{H}_{22} \mathrm{O}\right)$ shows large mixing ratios for a narrow wind sector but only for wind speeds larger than $\sim 3 \mathrm{~m} \mathrm{~s}^{-1}$. Since these wind speeds occur only in the middle of the day at that site (Figure 4), we can hypothesise that either this compound is produced by a photoreaction process, or that it is rapidly depleted during its travel very quickly. Using the $3 \mathrm{~m} \mathrm{~s}^{-1}$ thresholds observed in Figure 11, we could infer a travel time of $\sim 2.5 \mathrm{~min}$ from the farm. This would mean that those compounds would be depleted in 2.5 min time. A third hypothesis would be that those compounds may be transported from an incinerator, which is $2 \mathrm{~km}$ away, and was identified as an $\mathrm{SO}_{2}$ source by Loubet et al. (2012). This incinerator, which can emit both day and night is however a bit more west than the farm $(225 \mathrm{deg} / \mathrm{N})$. Therefore, the source of the VOC behaving like by $\mathrm{m} / \mathrm{z} 187.148$ may rather be the farm. Compounds that behave similarly are heavy ions (m/z 201.139, and m/z 201.233) suggesting also oxidised compounds.

\section{Conclusions}

We found that the PTR-Qi-TOF-MS was sensitive enough to measure fluxes of 264 VOC by eddy covariance (77 emitting and 187 depositing, fluxes > 3 LODf) above a wheat canopy during a mature and a senescing period. The fact that we measured less emitting compounds than depositing can be explained by the high atmospheric mixing ratios observed for the depositing compounds. In particular, the nearby farm contributed to increasing the ambient concentration of some VOC, most of which quite heavy, including monoterpenes, and acetic acid.

The eddy-covariance flux computation was analysed in detail showing that the WPL correction was negligible (most of the time lower than $2 \%$ ). Similarly, normalising by the $\mathrm{H}_{3} \mathrm{O}^{+} \mathrm{cps}$ at high frequency was shown to produce biases that were also negligible most of the time. We found a small high frequency loss but difficulties in analysing the frequency response of the noisy signals of most VOC. New developments in this field would be helpful Our measurements confirm that methanol is the most emitted compound over wheat, representing $62 \%$ of the summed VOC moles emitted by the crop. Acetone and acetaldehyde were also found to contribute significantly to the summed VOC emissions, confirming previous findings. However, we detected several compounds not previously reported as emitted by wheat. In particular, m/z $93.037\left(\mathrm{C}_{6} \mathrm{H}_{4} \mathrm{O}\right)$, was the second most emitted compound and may be released by decomposing organic matter. Moreover, substantial DMS emissions were measured which confirm earlier findings on the magnitude of the terrestrial DMS source and suggest that soils may be a significant source of DMS together with plants and litter.

Furthermore, we found that deposition of oxygenated VOC was large, with acidic compounds contributing largely to the summed deposition, together with hydroxyacetone. These compounds include acetic, formic and 4oxopentanal. For many compounds, deposition was larger during senescence, suggesting either an uptake process or a gas phase interaction with compounds emitted by the plant at that stage. These putative processes would need further investigations.

Overall, the summed VOC emissions amounted $36 \mathrm{~g} \mathrm{ha}^{-1}$ day $^{-1}$ and summed deposition amounted $-26 \mathrm{~g} \mathrm{ha}^{-1}$ day $^{-1}$, leading to a net flux of $\sim 10 \mathrm{~g} \mathrm{ha}^{-1} \mathrm{day}^{-1}$. When roughly extrapolated to the whole year, the summed VOC flux amounted around $2.5 \mathrm{~kg} \mathrm{C} \mathrm{ha}^{-1}$ year-1, an amount negligible compared to the $\mathrm{CO}_{2}$ flux $\left(17 \mathrm{Mg} \mathrm{C}^{-1} \mathrm{year}^{-1}\right)$. 
Using a PTR-Qi-TOF-MS to measure VOC fluxes over an ecosystem for a long period by eddy covariance allows clear identification of the compounds corresponding to each ion, as well as the calibration of a large number of gases.

\section{Code availability}

The Labview code to record the data and the R code used to compute the fluxes is on the following repository (available on demand): https://forgemia.inra.fr/Benjamin.Loubet/cov3er

\section{Data availability}

The complete hourly dataset is available as an Rdata file (COV3ER_2016_dataset.Rdata) containing the whole dataset, together with a data description file (COV3ER_2016_dataset-description.xlsx), and a script for reading and plotting the data (COV3ER_2016_dataset_make_graphs.R). The data and code to visualise are available here: https://data.inrae.fr/dataset.xhtml?persistentId=doi:10.15454/IRZ9XX .

\section{Supplement link}

Supplementary material includes a pdf document with supplementary figures and tables, and an xls file containing the averaged fluxes, mixing ratios, LODf (Table S2). Also available are three CSV files containing some correlation tables between VOC (Tables S3a, b, c).

\section{Authors contribution}

Benjamin Loubet: Conceptualization, data curation, formal analysis, funding acquisition, Investigation, Methodology, project administration, software, supervision, validation, visualization, writing-original draft, writing-review and editing. Pauline Buysse: Investigation, Data curation, Resources, writing - review \& editing. Lais Gonzaga-Gomez: formal analysis, investigation, Software, writing - review \& editing. Florence Lafouge: Investigation, Data curation, Resources, writing - review \& editing. Raluca Ciuraru: Investigation, Resources, validation, writing - review \& editing. Céline Decuq: Data Curation, Investigation, Resources, validation. Julien Kammer: Data Curation, Investigation, Resources, validation, writing - review \& editing. Sandy Bsaibes: writing - review \& editing. Christophe Boissard: Resources. Brigitte Durand: Resources, investigation. JeanChristophe Gueudet: Resources. Olivier Fanucci: Resources. Olivier Zurfluh: Resources. Letizia Abis: formal analysis, investigation, software, writing - review \& editing. Nora Zannoni: Investigation, writing - review \& editing. François Truong: Resources, investigation. Dominique Baisnée: Resources, investigation. RolandSarda Esteve: Resources. Michael Staudt: writing - review \& editing. Valérie Gros: Supervision, Resources, funding acquisition, investigation, methodology, writing - review \& editing.

\section{Competing interests}




\section{Acknowledgements}

We acknowledge funding by ADEME (COV3ER, $n^{\circ} 1562$ C0032), ANAEE-FR services (ANR project $n^{\circ} 11$-INBS0001). The data analysis was supported by the regional funding R2DS and the ADEME projects DICOV (grant $\mathrm{n}^{\circ}$ 1662c0020), AGRIMULTUPOL (grant number 1703C0012). Sandy Bsaibes acknowledges the European Union's Horizon 2020 research and innovation program under the Marie-Sklodowska-Curie grant agreement No 674911-

IMPACT. The measurements were performed on the ICOS FR-GRI site. We acknowledge Dominique Tristan for letting access to the field.

\section{References}

Abis, L. et al., 2018. Profiles of volatile organic compound emissions from soils amended with organic waste products. Sci Total Environ, 636: 1333-1343.

Ammann, C., Brunner, A., Spirig, C. and Neftel, A., 2006. Technical note: Water vapour concentration and flux measurements with PTR-MS. Atmospheric Chemistry and Physics, 6: 4643-4651.

Ashmore, M.R., 2005. Assessing the future global impacts of ozone on vegetation. Plant Cell and Environment, 28(8): 949-964.

Aubinet, M. et al., 2000. Estimates of the annual net carbon and water exchange of forests: The EUROFLUX methodology. Advances in Ecological Research, Vol 30, 30: 113-175.

Avnery, S., Mauzerall, D.L., Liu, J.F. and Horowitz, L.W., 2011. Global crop yield reductions due to surface ozone exposure: 1. Year 2000 crop production losses and economic damage. Atmos. Environ., 45(13): 22842296.

Baasandorj, M., Millet, D.B., Hu, L., Mitroo, D. and Williams, B.J., 2015. Measuring acetic and formic acid by proton-transfer-reaction mass spectrometry: sensitivity, humidity dependence, and quantifying interferences. Atmospheric Measurement Techniques, 8(3): 1303-1321.

Bachy, A. et al., 2020. Dynamics and mechanisms of volatile organic compound exchanges in a winter wheat field. Atmos. Environ., 221.

Bachy, A. et al., 2018. Methanol exchange dynamics between a temperate cropland soil and the atmosphere. Atmos. Environ., 176: 229-239.

Bachy, A. et al., 2016. Are BVOC exchanges in agricultural ecosystems overestimated? Insights from fluxes measured in a maize field over a whole growing season. Atmospheric Chemistry and Physics, 16(8): 5343-5356.

Bamberger, I. et al., 2010. BVOC fluxes above mountain grassland. BIOGEOSCIENCES, 7(5): 1413-1424.

Bamberger, I. et al., 2011. Deposition fluxes of terpenes over grassland. Journal of Geophysical Research, 116(D14).

Berhongaray, G., Verlinden, M.S., Broeckx, L.S., Janssens, I.A. and Ceulemans, R., 2017. Soil carbon and belowground carbon balance of a short-rotation coppice: assessments from three different approaches. Global Change Biology Bioenergy, 9(2): 299-313.

Brilli, F. et al., 2016. Rapid leaf development drives the seasonal pattern of volatile organic compound (VOC) fluxes in a "coppiced' bioenergy poplar plantation. Plant Cell and Environment, 39(3): 539-555. 
Carozzi, M., Loubet, B., Acutis, M., Rana, G. and Ferrara, R.M., 2013. Inverse dispersion modelling highlights the efficiency of slurry injection to reduce ammonia losses by agriculture in the Po Valley (Italy). Agricultural and Forest Meteorology, 171: 306-318.

Carrión, O. et al., 2017. Methanethiol-dependent dimethylsulfide production in soil environments. The ISME Journal, 11(10): 2379-2390.

Chaignaud, P. et al., 2018. Methanol consumption drives the bacterial chloromethane sink in a forest soil. Isme Journal, 12(11): 2681-2693.

Cojocariu, C. et al., 2005. The effect of ozone on the emission of carbonyls from leaves of adult Fagus sylvatica. Plant Cell and Environment, 28(5): 603-611.

Copeland, N., Cape, J.N. and Heal, M.R., 2012. Volatile organic compound emissions from Miscanthus and short rotation coppice willow bioenergy crops. Atmos. Environ., 60: 327-335.

Crespo, E. et al., 2013. Volatile organic compound emissions from elephant grass and bamboo cultivars used as potential bioethanol crop. Atmos. Environ., 65: 61-68.

Custer, T. and Schade, G., 2007. Methanol and acetaldehyde fluxes over ryegrass. Tellus Series B-Chemical and Physical Meteorology, 59(4): 673-684.

Das, M. et al., 2003. Measurements of hydrocarbon air-surface exchange rates over maize. Atmos. Environ., 37(16): 2269-2277.

Davison, B. et al., 2008. Cut-induced VOC emissions from agricultural grasslands. Plant Biology, 10(1): 76-85.

De Gouw, J.A., Howard, C.J., Custer, T.G., Baker, B.M. and Fall, R., 2000. Proton-transfer chemical-ionization mass spectrometry allows real-time analysis of volatile organic compounds released from cutting and drying of crops. Environmental Science \& Technology, 34(12): 2640-2648.

Effmert, U., Kalderas, J., Warnke, R. and Piechulla, B., 2012. Volatile Mediated Interactions Between Bacteria and Fungi in the Soil. Journal of Chemical Ecology, 38(6): 665-703.

Eller, A.S.D. et al., 2011. Volatile organic compound emissions from switchgrass cultivars used as biofuel crops. Atmos. Environ., 45(19): 3333-3337.

Fares, S., Oksanen, E., Lannenpaa, M., Julkunen-Tiitto, R. and Loreto, F., 2010. Volatile emissions and phenolic compound concentrations along a vertical profile of Populus nigra leaves exposed to realistic ozone concentrations. Photosynthesis Research, 104(1): 61-74.

Fares, S. et al., 2012. Seasonal cycles of biogenic volatile organic compound fluxes and concentrations in a California citrus orchard. Atmospheric Chemistry and Physics, 12(20): 9865-9880.

Feilberg, A., Bildsoe, P. and Nyord, T., 2015. Application of PTR-MS for Measuring Odorant Emissions from Soil Application of Manure Slurry. Sensors, 15(1): 1148-1167.

Filella, I., Wilkinson, M.J., Llusia, J., Hewitt, C.N. and Penuelas, J., 2007. Volatile organic compounds emissions in Norway spruce (Picea abies) in response to temperature changes. Physiologia Plantarum, 130(1): 5866.

Fruekilde, P., Hjorth, J., Jensen, N.R., Kotzias, D. and Larsen, B., 1998. Ozonolysis at vegetation surfaces: A source of acetone, 4-oxopentanal, 6-methyl-5-hepten-2-one, and geranyl acetone in the troposphere. Atmos. Environ., 32(11): 1893-1902.

Gabriel, R., Schafer, L., Gerlach, C., Rausch, T. and Kesselmeier, J., 1999. Factors controlling the emissions of volatile organic acids from leaves of Quercus ilex L. (Holm oak). Atmos. Environ., 33(9): 1347-1355. 
Gallagher, M.W. et al., 2000. Assessment of a relaxed eddy accumulation for measurements of fluxes of biogenic volatile organic compounds: study over arable crops and a mature beech forest. Atmos. Environ., 34(18):

Gonzaga Gomez, L. et al., 2019. Comparative study of biogenic volatile organic compounds fluxes by wheat, maize and rapeseed with dynamic chambers over a short period in northern France. Atmos. Environ., 214: 116855.

Graus, M. et al., 2011. Comparison of VOC emissions from conventional and alternative biofuel crops. Abstracts

Graus, M. et al., 2013. Biosphere-atmosphere exchange of volatile organic compounds over C4 biofuel crops. Atmos. Environ., 66: 161-168.

Harley, P., Greenberg, J., Niinemets, Ü. and Guenther, A., 2007. Environmental controls over methanol emission from leaves. Biogeosciences, 4(6): 1083-1099.

Hatch, L.E. et al., 2017. Multi-instrument comparison and compilation of non-methane organic gas emissions from biomass burning and implications for smoke-derived secondary organic aerosol precursors. Atmospheric Chemistry and Physics, 17(2): 1471-1489.

Helmig, D. et al., 1998. Vertical profiling and determination of landscape fluxes of biogenic nonmethane hydrocarbons within the planetary boundary layer in the Peruvian Amazon. Journal of Geophysical

Hobbs, P.J., Webb, J., Mottram, T.T., Grant, B. and Misselbrook, T.M., 2004. Emissions of volatile organic compounds originating from UK livestock agriculture. Journal of the Science of Food and Agriculture, 84(11): 1414-1420.

Holopainen, J.K., Kivimaenpaa, M. and Nizkorodov, S.A., 2017. Plant-derived Secondary Organic Material in the

IPCC, 2018. IPCC, 2018: Global Warming of $1.5^{\circ}$ C.An IPCC Special Report on the impacts of global warming of $1.5^{\circ} \mathrm{C}$ above pre-industrial levels and

related global greenhouse gas emission pathways, in the context of strengthening the global response to the threat of climate change,

sustainable development, and efforts to eradicate poverty [Masson-Delmotte, V., P. Zhai, H.-O. Pörtner, D. Roberts, J. Skea, P.R. Shukla,

A. Pirani, W. Moufouma-Okia, C. Péan, R. Pidcock, S. Connors, J.B.R. Matthews, Y. Chen, X. Zhou, M.I. Gomis, E. Lonnoy, T. Maycock,

M. Tignor, and T. Waterfield (eds.)]. Intergovernmental Panel on Climate Change.

Jacob, D.J. et al., 2005. Global budget of methanol: Constraints from atmospheric observations. Journal of Geophysical Research-Atmospheres, 110(D8).

Jardine, K. et al., 2011. Ecosystem-scale compensation points of formic and acetic acid in the central Amazon. Biogeosciences, 8(12): 3709-3720.

Jardine, K. et al., 2015. Dimethyl sulfide in the Amazon rain forest. Global Biogeochemical Cycles, 29(1): 19-32. chemistry. Atmos. Chem. Phys., 16(1): 277-292. 
Kammer, J. et al., 2020. Characterization of particulate and gaseous pollutants from a French dairy and sheep farm. Science of the Total Environment, 712.

Kanda, K., Tsuruta, H. and Minami, K., 1995. Emissions of Biogenic Sulfur Gases from Maize and Wheat Fields. Soil Sci Plant Nutr, 41(1): 1-8.

Karl, M., Guenther, A., Koble, R., Leip, A. and Seufert, G., 2009a. A new European plant-specific emission inventory of biogenic volatile organic compounds for use in atmospheric transport models. Biogeosciences, 6(6): 1059-1087.

Karl, T., Curtis, A.J., Rosenstiel, T.N., Monson, R.K. and Fall, R., 2002. Transient releases of acetaldehyde from tree leaves - products of a pyruvate overflow mechanism? Plant Cell and Environment, 25(9): 1121-1131.

Karl, T. et al., 2001. Eddy covariance measurements of oxygenated volatile organic compound fluxes from crop harvesting using a redesigned proton-transfer-reaction mass spectrometer. Journal of Geophysical Research-Atmospheres, 106(D20): 24157-24167.

Karl, T. et al., 2009b. Rapid formation of isoprene photo-oxidation products observed in Amazonia. Atmospheric Chemistry and Physics, 9(20): 7753-7767.

Karl, T. et al., 2012. Selective measurements of isoprene and 2-methyl-3-buten-2-ol based on NO+ ionization mass spectrometry. Atmospheric Chemistry and Physics, 12(24): 11877-11884.

Karl, T. et al., 2010. Efficient Atmospheric Cleansing of Oxidized Organic Trace Gases by Vegetation. Science, 330(6005): 816-819.

Karl, T. et al., 2005. Senescing grass crops as regional sources of reactive volatile organic compounds. Journal of Geophysical Research-Atmospheres, 110(D15).

Keenan, T., Niinemets, U., Sabate, S., Gracia, C. and Penuelas, J., 2009. Process based inventory of isoprenoid emissions from European forests: model comparisons, current knowledge and uncertainties. Atmospheric Chemistry and Physics, 9(12): 4053-4076.

Keskitalo, J., Bergquist, G., Gardestrom, P. and Jansson, S., 2005. A cellular timetable of autumn senescence. Plant Physiology, 139(4): 1635-1648.

Kesselmeier, J., Bode, K., Gerlach, C. and Jork, E.M., 1998. Exchange of atmospheric formic and acetic acids with trees and crop plants under controlled chamber and purified air conditions. Atmos. Environ., 32(10): 1765-1775.

Kiraly, Z., 1962. Phenol Content in Rust Infected and Nitrogen Fertilized Wheat Leaves. Phytopathology, 52(8): 738-\&.

Klemm, O., Milford, C., Sutton, M.A., Spindler, G. and van Putten, E., 2002. A climatology of leaf surface wetness. Theor Appl Climatol, 71(1-2): 107-117.

Konig, G. et al., 1995. Relative Contribution of Oxygenated Hydrocarbons to the Total Biogenic Voc Emissions of Selected Mid-European Agricultural and Natural Plant-Species. Atmos. Environ., 29(8): 861-874.

Kormann, R. and Meixner, F.X., 2001. An analytical footprint model for non-neutral stratification. BoundaryLayer Meteorology, 99(2): 207-224.

Koss, A.R. et al., 2018. Non-methane organic gas emissions from biomass burning: identification, quantification, and emission factors from PTR-ToF during the FIREX 2016 laboratory experiment. Atmospheric Chemistry and Physics, 18(5): 3299-3319. 
Laffineur, Q. et al., 2012. Abiotic and biotic control of methanol exchanges in a temperate mixed forest. Atmospheric Chemistry and Physics, 12(1): 577-590.

Lang-Yona, N. et al., 2010. The chemical and microphysical properties of secondary organic aerosols from Holm Oak emissions. Atmospheric Chemistry and Physics, 10(15): 7253-7265.

Langford, B., Acton, W., Ammann, C., Valach, A. and Nemitz, E., 2015. Eddy-covariance data with low signalto-noise ratio: time-lag determination, uncertainties and limit of detection. Atmos. Meas. Tech., 8(10): 4197-4213.

Lathière, J., Hewitt, C.N. and Beerling, D.J., 2010. Sensitivity of isoprene emissions from the terrestrial biosphere to 20th century changes in atmospheric $\mathrm{CO} 2$ concentration, climate, and land use. Global Biogeochemical Cycles, 24(1).

Laufs, S. et al., 2016. Diurnal fluxes of HONO above a crop rotation. Atmos. Chem. Phys. Discuss., 2016: 1-28.

Leuning, R., 2007. The correct form of the Webb, Pearman and Leuning equation for eddy fluxes of trace gases in steady and non-steady state, horizontally homogeneous flows. Boundary-Layer Meteorology, 123(2): 263-267.

Link, M.F., Nguyen, T.B., Bates, K., Müller, J.-F. and Farmer, D.K., 2020. Can Isoprene Oxidation Explain High Concentrations of Atmospheric Formic and Acetic Acid over Forests? ACS Earth and Space Chemistry, 4(5): 730-740.

Loubet, B. et al., 2018. Evaluation of a new inference method for estimating ammonia volatilisation from multiple agronomic plots. Biogeosciences, 15(11): 3439-3460.

Loubet, B. et al., 2012. Investigating the stomatal, cuticular and soil ammonia fluxes over a growing tritical crop under high acidic loads. Biogeosciences, 9(4): 1537-1552.

Loubet, B. et al., 2010. An inverse model to estimate ammonia emissions from fields. European Journal of Soil Science, 61(5): 793-805.

Loubet, B. et al., 2011. Carbon, nitrogen and Greenhouse gases budgets over a four years crop rotation in northern France. Plant and Soil, 343(1-2): 109--137.

Makkonen, R. et al., 2012. Air pollution control and decreasing new particle formation lead to strong climate warming. Atmospheric Chemistry and Physics, 12(3): 1515-1524.

Messina, P. et al., 2016. Global biogenic volatile organic compound emissions in the ORCHIDEE and MEGAN models and sensitivity to key parameters. Atmospheric Chemistry and Physics, 16(22): 14169-14202.

Michele, N.-M., MacDonald, R.C., Jennifer, J.F., Cheryl, L.W. and Fall, R., 1995. Methanol Emission from Leaves: Enzymatic Detection of Gas-Phase Methanol and Relation of Methanol Fluxes to Stomatal Conductance and Leaf Development. Plant Physiology, 108(4): 1359-1368.

Mielnik, A., Link, M., Mattila, J., Fulgham, S.R. and Farmer, D.K., 2018. Emission of formic and acetic acids from two Colorado soils. Environmental Science-Processes \& Impacts, 20(11): 1537-1545.

Miresmailli, S. et al., 2013. Impacts of herbaceous bioenergy crops on atmospheric volatile organic composition and potential consequences for global climate change. Global Change Biology Bioenergy, 5(4): 375-383.

Misztal, P.K., Heal, M.R., Nemitz, E. and Cape, J.N., 2012. Development of PTR-MS selectivity for structural isomers: Monoterpenes as a case study. International Journal of Mass Spectrometry, 310: 10-19.

Misztal, P.K. et al., 2014. Airborne flux measurements of biogenic isoprene over California. Atmospheric Chemistry and Physics, 14(19): 10631-10647. 
Monks, P.S. et al., 2015. Tropospheric ozone and its precursors from the urban to the global scale from air quality to short-lived climate forcer. Atmos. Chem. Phys., 15(15): 8889-8973.

Morawe, M. et al., 2017. Acidotolerant Bacteria and Fungi as a Sink of Methanol-Derived Carbon in a Deciduous Forest Soil. Frontiers in Microbiology, 8.

Morrison, E.C., Drewer, J. and Heal, M.R., 2016. A comparison of isoprene and monoterpene emission rates from the perennial bioenergy crops short-rotation coppice willow and Miscanthus and the annual arable crops wheat and oilseed rape. Global Change Biology Bioenergy, 8(1): 211-225.

Mozaffar, A. et al., 2018. Biogenic volatile organic compound emissions from senescent maize leaves and a comparison with other leaf developmental stages. Atmos. Environ., 176: 71-81.

Muller, M. et al., 2010. First eddy covariance flux measurements by PTR-TOF. Atmospheric Measurement Techniques, 3(2): 387-395.

Nguyen, T.B. et al., 2015. Rapid deposition of oxidized biogenic compounds to a temperate forest. Proc Natl Acad Sci U S A, 112(5): E392-401.

Ni, J.-Q., Robarge, W.P., Xiao, C. and Heber, A.J., 2012. Volatile organic compounds at swine facilities: A critical review. Chemosphere, 89(7): 769-788.

Niinemets, U., Fares, S., Harley, P. and Jardine, K.J., 2014. Bidirectional exchange of biogenic volatiles with vegetation: emission sources, reactions, breakdown and deposition. Plant Cell and Environment, 37(8): 1790-1809.

Niinemets, U. et al., 2011. Estimations of isoprenoid emission capacity from enclosure studies: measurements, data processing, quality and standardized measurement protocols. Biogeosciences, 8(8): 2209-2246.

Papageorgiou, A., Voutsa, D. and Papadakis, N., 2014. Occurrence and fate of ozonation by-products at a fullscale drinking water treatment plant. SCIENCE OF THE TOTAL ENVIRONMENT, 481: 392-400.

Park, J.-H. et al., 2013a. Active Atmosphere-Ecosystem Exchange of the Vast Majority of Detected Volatile Organic Compounds. Science, 341(6146): 643-647.

Park, J.H. et al., 2013b. Eddy covariance emission and deposition flux measurements using proton transfer reaction - time of flight - mass spectrometry (PTR-TOF-MS): comparison with PTR-MS measured vertical gradients and fluxes. Atmospheric Chemistry and Physics, 13(3): 1439-1456.

Personne, E. et al., 2015. Investigating sources and sinks for ammonia exchanges between the atmosphere and a wheat canopy following slurry application with trailing hose. Agricultural and Forest Meteorology, 207: $11-23$.

Portillo-Estrada, M., Ariza-Carricondo, C. and Ceulemans, R., 2020. Outburst of senescence-related VOC emissions from a bioenergy poplar plantation. Plant Physiology and Biochemistry, 148: 324-332.

Portillo-Estrada, M., Zenone, T., Arriga, N. and Ceulemans, R., 2018. Contribution of volatile organic compound fluxes to the ecosystem carbon budget of a poplar short-rotation plantation. Global Change Biology Bioenergy, 10(6): 405-414.

Potier, E. et al., 2017. Chemical reaction rates of ozone in water infusions of wheat, beech, oak and pine leaves of different ages. Atmos. Environ., 151: 176-187.

Potier, E. et al., 2015. Multi layer modelling of ozone fluxes on winter wheat reveals large deposition on wet senescing leaves. Agricultural and Forest Meteorology, 211: 58-71. 

exchange between a boreal pine forest and the atmosphere. Biogeosciences, 12(19): 5753-5770.

Ruuskanen, T.M. et al., 2011. Eddy covariance VOC emission and deposition fluxes above grassland using PTRTOF. Atmospheric Chemistry and Physics, 11(2): 611-625.

Schade, G.W. and Goldstein, A.H., 2001. Fluxes of oxygenated volatile organic compounds from a ponderosa pine plantation. Journal of Geophysical Research-Atmospheres, 106(D3): 3111-3123.

Scholler, C.E.G., Gurtler, H., Pedersen, R., Molin, S. and Wilkins, K., 2002. Volatile metabolites from actinomycetes. Journal of Agricultural and Food Chemistry, 50(9): 2615-2621.

Seco, R., Penuelas, J. and Filella, I., 2007. Short-chain oxygenated VOCs: Emission and uptake by plants and atmospheric sources, sinks, and concentrations. Atmos. Environ., 41(12): 2477-2499.

Sindelarova, K. et al., 2014. Global data set of biogenic VOC emissions calculated by the MEGAN model over the last 30 years. Atmospheric Chemistry and Physics, 14(17): 9317-9341.

Spirig, C. et al., 2005. Eddy covariance flux measurements of biogenic VOCs during ECHO 2003 using proton transfer reaction mass spectrometry. Atmospheric Chemistry and Physics, 5: 465-481.

Staudt, M., Wolf, A. and Kesselmeier, J., 2000. Influence of environmental factors on the emissions of gaseous formic and acetic acids from orange (Citrus sinensis L.) foliage. Biogeochemistry, 48(2): 199-216.

Steeghs, M.M.L., Crespo, E. and Harren, F.J.M., 2007. Collision induced dissociation study of 10 monoterpenes for identification in trace gas measurements using the newly developed proton-transfer reaction ion trap mass spectrometer. International Journal of Mass Spectrometry, 263(2-3): 204-212.

Stockwell, C.E., 2016. Advanced measurements of undersampled globally significant biomass burning sources, University of Montana, Montana, USA.

Sulzer, P. et al., 2014. A Proton Transfer Reaction-Quadrupole interface Time-Of-Flight Mass Spectrometer (PTRQiTOF): High speed due to extreme sensitivity. International Journal of Mass Spectrometry, 368: 1-5.

Tani, A., Hayward, S., Hansel, A. and Hewitt, C.N., 2004. Effect of water vapour pressure on monoterpene measurements using proton transfer reaction-mass spectrometry (PTR-MS). International Journal of Mass Spectrometry, 239(2-3): 161-169.

Tani, A., Hayward, S. and Hewitta, C.N., 2003. Measurement of monoterpenes and related compounds by proton transfer reaction-mass spectrometry (PTR-MS). International Journal of Mass Spectrometry, 223(1-3): 561-578.

Venneman, J. et al., 2020. Respiratory CO2 Combined With a Blend of Volatiles Emitted by Endophytic Serendipita Strains Strongly Stimulate Growth of Arabidopsis Implicating Auxin and Cytokinin Signaling. Frontiers in Plant Science, 11(1343).

Vettikkat, L. et al., 2020. Significant emissions of dimethyl sulfide and monoterpenes by big-leaf mahogany trees: discovery of a missing dimethyl sulfide source to the atmospheric environment. Atmospheric Chemistry and Physics, 20(1): 375-389.

1115 Vuolo, R.M. et al., 2017. Nitrogen oxides and ozone fluxes from an oilseed-rape management cycle: the influence of cattle slurry application. BIOGEOSCIENCES, 14(8): 2225-2244.

Warneke, C. et al., 1999. Acetone, methanol, and other partially oxidized volatile organic emissions from dead plant matter by abiological processes: Significance for atmospheric HOx chemistry. GLOBAL BIOGEOCHEMICAL CYCLES, 13(1): 9-17. 
Webb, E.K., Pearman, G.I. and Leuning, R., 1980. Correction of flux measurements for density effects due to heat and water vapour transfer. Quarterly Journal of the Royal Meteorological Society, 106(447): 85-100.

Wienhold, F.G., Frahm, H. and Harris, G.W., 1994. MEASUREMENTS OF N2O FLUXES FROM FERTILIZED GRASSLAND USING A FAST-RESPONSE TUNABLE DIODE-LASER SPECTROMETER. Journal of Geophysical Research-Atmospheres, 99(D8): 16557-16567.

Wiss, F. et al., 2017. Net ecosystem fluxes and composition of biogenic volatile organic compounds over a maize field-interaction of meteorology and phenological stages. Global Change Biology Bioenergy, 9(11): 1627-1643.

Woo, H.R., Kim, H.J., Lim, P.O. and Nam, H.G., 2019. Leaf Senescence: Systems and Dynamics Aspects. In: S.S. Merchant (Editor), Annual Review of Plant Biology, Vol 70. Annual Review of Plant Biology, pp. 347 376.

Yáñez-Serrano, A.M. et al., 2021. GLOVOCS - Master compound assignment guide for proton transfer reaction mass spectrometry users. Atmos. Environ., 244: 117929.

Zenone, T. et al., 2016. Interaction between isoprene and ozone fluxes in a poplar plantation and its impact on air quality at the European level. Scientific Reports, 6.

1135 Zhao, J. et al., 2016. Volatile organic compound emissions from straw-amended agricultural soils and their relations to bacterial communities: A laboratory study. Journal of Environmental Sciences, 45: 257-269.

Zhou, P.T. et al., 2017. Boreal forest BVOC exchange: emissions versus in-canopy sinks. Atmospheric Chemistry and Physics, 17(23): 14309-14332. 